OPEN ACCESS

Edited by:

Jesús Navas-Castillo,

Institute of Subtropical

and Mediterranean Horticulture La

Mayora, Spain

Reviewed by:

Francis Onono Wamonje, University of Saskatchewan, Canada Martin Drucker, INRAE, Centre de recherche Grand

Est-Colmar, France

*Correspondence: Hideki Kondo

hkondo@okayama-u.ac.jp

Specialty section:

This article was submitted to

Virology,

a section of the journal

Frontiers in Microbiology

Received: 27 January 2020

Accepted: 09 March 2020

Published: 07 April 2020

Citation:

Kondo $\mathrm{H}$, Fujita $\mathrm{M}$, Hisano $\mathrm{H}$, Hyodo K, Andika IB and Suzuki N (2020) Virome Analysis of Aphid Populations That Infest the Barley Field: The Discovery of Two Novel Groups of Nege/Kita-Like Viruses and Other Novel RNA Viruses.

Front. Microbiol. 11:509. doi: 10.3389/fmicb.2020.00509

\section{Virome Analysis of Aphid Populations That Infest the Barley Field: The Discovery of Two Novel Groups of Nege/Kita-Like Viruses and Other Novel RNA Viruses}

\author{
Hideki Kondo ${ }^{*}$, Miki Fujita', Hiroshi Hisano', Kiwamu Hyodo', Ida Bagus Andika² and \\ Nobuhiro Suzuki ${ }^{1}$
}

${ }^{1}$ Institute of Plant Science and Resources (IPSR), Okayama University, Kurashiki, Japan, ${ }^{2}$ College of Plant Health and Medicine, Qingdao Agricultural University, Qingdao, China

Aphids (order Hemiptera) are important insect pests of crops and are also vectors of many plant viruses. However, little is known about aphid-infecting viruses, particularly their diversity and relationship to plant viruses. To investigate the aphid viromes, we performed deep sequencing analyses of the aphid transcriptomes from infested barley plants in a field in Japan. We discovered virus-like sequences related to nege/ kita-, flavi-, tombus-, phenui-, mononega-, narna-, chryso-, partiti-, and luteoviruses. Using RT-PCR and sequence analyses, we determined almost complete sequences of seven nege/kitavirus-like virus genomes; one of which was a variant of the Wuhan house centipede virus (WHCV-1). The other six seem to belong to four novel viruses distantly related to Wuhan insect virus 9 (WhIV-9) or Hubei nege-like virus 4 (HVLV4). We designated the four viruses as barley aphid RNA virus 1 to 4 (BARV-1 to -4). Moreover, some nege/kitavirus-like sequences were found by searches on the transcriptome shotgun assembly (TSA) libraries of arthropods and plants. Phylogenetic analyses showed that BARV-1 forms a clade with WHCV-1 and HVLV-4, whereas BARV2 to -4 clustered with WhIV-9 and an aphid virus, Aphis glycines virus 3. Both virus groups (tentatively designated as Centivirus and Aphiglyvirus, respectively), together with arthropod virus-like TSAs, fill the phylogenetic gaps between the negeviruses and kitaviruses lineages. We also characterized the flavi/jingmen-like and tombus-like virus sequences as well as other RNA viruses, including six putative novel viruses, designated as barley aphid RNA viruses 5 to 10. Interestingly, we also discovered that some aphid-associated viruses, including nege/kita-like viruses, were present in different aphid species, raising a speculation that these viruses might be distributed across different aphid species with plants being the reservoirs. This study provides novel information on the diversity and spread of nege/kitavirus-related viruses and other RNA viruses that are associated with aphids.

Keywords: negevirus, kitavirus, aphid, virome, RNA seq, barley, diversity, horizontal transmission 


\section{INTRODUCTION}

Aphids (order Hemiptera: superfamily Aphidoidae) are phloem feeders and important insect pests that affect a wide range of crops. Aphid infestation can reduce both the yield and quality of crops by direct feeding and transmitting symptomatic plant viruses (Powell et al., 2006). Many aphid species act as vectors for a number of agriculturally important plant viruses ( $\mathrm{Ng}$ and Perry, 2004; Brault et al., 2010). Most aphid-vectored plant viruses do not replicate within the aphids and are transmitted by either a non-circulative (non-persistent) or a circulative (persistent) manner (Ng and Perry, 2004; Whitfield et al., 2015; Dader et al., 2017); however, some plant rhabdoviruses (negative-sense RNA genome, family Rhabdoviridae) are transmitted by aphids through the circulative (persistent) manner and replicate within their vectors (Whitfield et al., 2018).

In cereal crops (within the family Poaceae), such as wheat (Triticum aestivum L.) and barley (Hordeum vulgare L.), aphids can cause great yield losses by directly feeding on the phloem sap and more significantly by transmitting several yellow dwarf disease-causing viruses (Jarosova et al., 2013; Krueger et al., 2013), such as barley yellow dwarf, cereal yellow dwarf and wheat yellow dwarf viruses (positive-sense RNA viruses, genera Luteovirus and Polerovirus, family Luteoviridae) (King et al., 2011). These viruses are transmitted in a circulative (persistent) and non-propagative manner by common aphid species that infest cereals, such as the bird cherry-oat aphid (Rhopalosiphum padi), corn leaf aphid (R. maidis), greenbugs (Schizaphis graminum), English grain aphid (Sitobion avenae), and rose-grain aphid (Metopolophium dirhodum) (Miller et al., 2002; Parry et al., 2012).

In addition to harboring numerous plant viruses, aphids are known to host several insect-specific single stranded DNA viruses [Myzus persicae densovirus (MpDNV) and Dysaphis plantaginea densovirus (DplDNV)] (van Munster et al., 2003; Ryabov et al., 2009) and positive-sense RNA viruses, the latter of which includes three picornaviruses: the Rhopalosiphum padi virus (RhPV) and aphid lethal paralysis virus (ALPV), both of the family Dicistroviridae, and the Brevicoryne brassicae virus (BrBV) of the family Iflaviridae (Moon et al., 1998; van Munster et al., 2002; Ryabov, 2007); and two unclassified RNA viruses: rosy apple aphid virus (a calici-like virus) and Acyrthosiphon pisum virus (APV) (distantly related to the members of the family Solinviviridae) (vandenHeuvel et al., 1997; Ryabov et al., 2009). Many of these viruses were discovered because of their phenotype alternations of the host aphids (Teixeira et al., 2016). More recently, analyses using next-generation sequencing (NGS) have identified several novel aphid-infecting viruses, including six positive-sense RNA viruses: three flavi-like viruses [Macrosiphum euphorbiae virus 1 (MeV-1); two jingmenviruses, Wuhan aphid virus 1 and 2 (WhAV-1 and -2)] (Shi et al., 2016b; Teixeira et al., 2016), a tetra-like virus (Aphis glycine virus 2), a negelike virus [Aphis glycine virus 3 (ApGlV-3)] (Feng et al., 2017) and a sobemo-like virus (Macrosiphum euphorbiae virus 3) (Teixeira et al., 2018); a negative-sense RNA phlebolike virus (Aphis citricidus bunyavirus) (Zhang et al., 2019); and a DNA densovirus (Macrosiphum euphorbiae virus 2) (Teixeira et al., 2018). Nevertheless, little is known about the viromes of aphid populations, particularly those that infest cereal plants in the field.

During the past decades, an increasing number of the novel "insect-infecting viruses" have been identified from mosquitoes (order Diptera). These viruses have a host range that is restricted to insects and are related to human arthropod-borne viral pathogens (so called arboviruses), such as dengue, Zika and West Nile viruses (family Flaviviridae), chikungunya virus (family Togaviridae) and Rift Valley fever virus (family Phenuiviridae) (Bolling et al., 2015). One of these insect-infecting virus groups has been proposed as the taxon "Negevirus," consisting of alpha-like viruses from mosquitos and sandflies (order Diptera) (Vasilakis et al., 2013; Vasilakis and Tesh, 2015). Negevirus particles are likely "spherical or elliptical" in shape with diameter of 45-55 nm (Vasilakis et al., 2013; Nabeshima et al., 2014; Kawakami et al., 2016; O'Brien et al., 2017; Zhao et al., 2019). Their genomes consist of a non-segmented, positive-sense RNA, approximately 9 to $10 \mathrm{~kb}$ in length and comprises three open reading frames (ORF). The second and third ORFs encode two structural proteins, a predicted glycoprotein (ORF2), and a predicted membrane protein SP24 (ORF3) (Kuchibhatla et al., 2014; Fujita et al., 2017; Zhao et al., 2019; Colmant et al., 2020). Based on phylogenetic analysis, this taxon could be separated into two groups at the genus level, namely "Nelorpivirus" and "Sandewavirus" (Kallies et al., 2014). Negeviruses are distantly related to members of three plant virus genera, Cilevirus, Higrevirus, and Blunervirus (Vasilakis et al., 2013; Kallies et al., 2014; Nunes et al., 2017; Ramos-González et al., 2020). These genera have recently been assigned as the members of the family Kitaviridae (Walker et al., 2019). Kitaviruses have bi-, tri- or tetra-partite positive-sense RNA genomes (Locali-Fabris et al., 2006; Melzer et al., 2013; Hao et al., 2018), and some of them, such as citrus leprosis virus cytoplasmic type (CiLV$\mathrm{C}$, a cilevirus, which is prevalent in several countries of the American continent), have non-enveloped bacilliform particles and are transmitted by false spider mites, Brevipalpus spp. (class Arachnida) (Tassi et al., 2017; Freitas-Astua et al., 2018). Recently, a meta-transcriptomic approach on invertebrates expanded the diversity of nege- and nege-like viruses infecting or associated with mosquitos and flies (Webster et al., 2015, 2016; Shi et al., 2017; Medd et al., 2018; Sadeghi et al., 2018; Pettersson et al., 2019) and other invertebrates (Shi et al., 2016a; Debat, 2017; Feng et al., 2017; Nunes et al., 2017; Schoonvaere et al., 2018; Kondo et al., 2019). Nevertheless, there is still very limited information about the relationships between negeviruses and kitaviruses and also the evolutionary history of these two virus groups.

In this study, a meta-transcriptomic approach was used to investigate the viromes of aphid populations collected from a barley field for three consecutive years, 2016-2018. We identified at least 60 virus-like sequence contigs related to RNA viruses such as nege/kita-, flavi/jingmen-, tombus-, phenui- and luteoviruses, including eight putative novel RNA viruses. In particular, our study reveals the new nege/kita-like virus lineages with the members that are associated with aphid species and, thus, 
enhances our knowledge on the diversity and evolution of insect viruses that are related to plant viral pathogens.

\section{MATERIALS AND METHODS}

\section{Collection of Aphids and Species Identification}

Collection of aphids were performed in the experimental field at the Institute of Plant Science and Resources (IPSR) in Okayama University, Kurashiki, Japan ( $34^{\circ} 59^{\prime} \mathrm{N}$ and $\left.133^{\circ} 77^{\prime} \mathrm{E}\right)$ on April and May in 2016-2018. Aphids (total 15 aphid samples) were obtained from the colonies that infest leaves and ears of barley cultivar "Golden Promise", "Morex", "Kikai Hadaka", "Minori Mugi", "Ryofu", "Kobin Katagi”, and three landraces (OUK327, OUU094, and OUU659), and then aphids samples were stored at $-80^{\circ} \mathrm{C}$ until further analysis.

To determine the aphid species, a 658-bp fragment of mitochondrial DNA from the $5^{\prime}$ region of the mitochondrial cytochrome c oxidase subunit 1 (COI) gene, was analyzed (Foottit et al., 2008). Total genomic DNA was extracted from a portion of each aphid sample by using DNeasy Blood and Tissue Kit (Qiagen, Venlo, Netherlands). The COI sequence of mitochondrial DNA was amplified by PCR using QuickTaq HS Dye Mix (Toyobo, Osaka, Japan) with the primer pair "LepF and LepR" (Supplementary Table S1; Foottit et al., 2008). PCR fragments were purified using the Wizard SV Gel and PCR Clean-Up System (Promega, United States) and then sequenced using the conventional Sanger sequencing method with an ABI3100 DNA sequencer (Applied Biosystems, Foster City, CA, United States). The amplified COI fragments were subjected to a BlastN search and Neighbor Joining (NJ) tree construction (see below).

\section{RNA Extraction and RT-PCR}

Total RNA from each aphid sample (pools of roughly 2040 individual aphids from each colony) was extracted using TaKaRa RNAiso Plus Reagent (TaKaRa Biotech. Co., Shiga, Japan), following the manufacturer's instructions. The total RNA fraction was analyzed by electrophoresis in a $1 \%(\mathrm{~W} / \mathrm{V})$ agarose gel in $1 \times$ TAE buffer. For reverse transcription (RT)PCR to detect virus-like sequences, cDNAs were synthesized using MMLV reverse transcriptase (Thermo Fisher Scientific, Waltham, MA, United States) with random hexamers, following the manufacturer's instructions. The cDNAs were then used as templates for PCR amplification with QuickTaq HS Dye Mix. The primer sets used to amplify virus-like sequences are provided in Supplementary Table S1. The 16S ribosomal RNA of aphids was used as a reference target gene for RT-PCR using a primer set "Apisum16S_F and Apisum16S_R" for Acyrthosiphon pisum (Supplementary Table S1; Koramutla et al., 2016). To confirm the presence of primary and secondary parasitoid wasps, we selected two primer sets "L.testa_RpL3_F and L.testa_RpL3_R" and "DcarpF and DcarpR" for amplification of the ribosomal protein L3 (RpL3) gene of a putative primary parasitoid species (Lysiphlebus testaceipes, Hymenoptera: Braconidae) (this study) and the $16 \mathrm{~S}$ rRNA gene of a putative secondary parasitoid species (Dendrocerus carpenteri, Hymenoptera: Megaspilidae) (Supplementary Table S1; Chen et al., 2006). PCR conditions used were as follows: an initial denaturation step at $94^{\circ} \mathrm{C}$ for $2 \mathrm{~min}$; followed by 30 or 35 cycles of: denaturing at $94^{\circ} \mathrm{C}$ for 10 seconds, annealing at $53^{\circ} \mathrm{C}$ or $55^{\circ} \mathrm{C}$ for 30 seconds, then extension at $72^{\circ} \mathrm{C}$ for $1 \mathrm{~min}$, then finishing with a final extension step at $72^{\circ} \mathrm{C}$ for $10 \mathrm{~min}$. PCR products were then purified and subjected to Sanger sequencing.

To determine the major uncertain or unknown regions of virus-like sequences, RT-PCR was performed using the specific primer sets, and PCR fragments were then sequenced using the Sanger method. Sequences of the primers used in the RTPCR are provided listed in Supplementary Table S1 or are available upon request.

\section{Next-Generation Sequencing and Read Assembly}

Total RNA fractions were prepared separately from 15 aphid samples (each population from a single colony) and according to the year of aphid collection, pooled into three groups: pool-1 (total $81.9 \mu \mathrm{g}$, RNA integrity number: RIN = 8.1) consisted of samples from 2016 ( 5 aphid populations, BaA116-1 to -5), pool-2 (total $12.4 \mu \mathrm{g}$, RIN = 9.1) consisted of samples from 2017 (2 aphid populations, BaA2-17-6 and -7) and pool-3 (total $36.9 \mu \mathrm{g}$, RIN = 9.1) consisted of samples from 2018 (8 aphid populations, BaA3-18-8 to -16) (Table 1). Each RNA sample pool was depleted of rRNA using a RiboZero kit (Illumina, San Diego, CA, United States) and then used for synthesis of a cDNA library using the TruSeq RNA Sample Preparation kit v2 (Illumina). The cDNA library obtained was subjected to deep sequencing using the Illumina HiSeq 2000 or 4000 platform (Illumina, pair-end 100 bp reads). Deep-sequencing was performed by Macrogen Inc (Tokyo, Japan). Raw reads (pool-1: 58,056,740; poo1-2: 58,030,114 and pool-3: $53,125,246)$ were trimmed by removing the adapter sequences and de novo assembled using the CLC Genomics Workbench version 11 (CLC Bio-Qiagen, Aarhus, Denmark). The assembled-contigs derived from each sample pool (over $1.0 \mathrm{~kb}$ contigs) were subjected to local Blast searches against the viral reference sequence (RefSeq) dataset of $\mathrm{NCBI}^{1}$ (the $E$-value cut-off is $>0.05$ for local BlastN). To roughly estimate the other sequence read origins for each NGS data set, we also conducted local Blast analyses against the following genome sequences: (1) aphid (R. padi) transcript data obtained from AphidBase $^{2}$; (2) insect parasitoid wasp ( $M$. demolitor, a larval lepidopteran endoparasitoid) transcript data from NCBI; (3) an aphid endosymbiotic bacterium (Buchnera aphidicola str. Ak, a blue alfalfa aphid Acyrthosiphon kondoi endosymbiont, accession no. CP002645) genome sequences; and (4) R. padi mitochondrion (accession no. KT447631) genome sequences. Mapping of sequence reads to each virus-like contigs or gap-filling virus-like sequences determined using RT-PCR was done using the Read Mapping algorithm of the CLC Genomics Workbench.

\footnotetext{
${ }^{1}$ https://www.ncbi.nlm.nih.gov

${ }^{2}$ https://bipaa.genouest.org/is/aphidbase/
} 
TABLE 1 | List of the aphid samples collected from the barley field.

\begin{tabular}{lll}
\hline Year sample no. & Aphid species ${ }^{\mathbf{1}}$ (BlastN best hit) & Barley cultivar or variety ${ }^{2}$ \\
\hline $\mathbf{2 0 1 6}$ & & \\
BaA1-16-1 & Rhopalosiphum padi & cv. Morex \\
BaA1-16-2 & Rhopalosiphum maidis & OUU659 \\
BaA1-16-3 & Rhopalosiphum padi & cv. Kikai Hadaka \\
BaA1-16-4 & Sitobion avenae & cv. Kikai Hadaka \\
BaA1-16-5 & Rhopalosiphum padi & cv. Golden Promise \\
$\mathbf{2 0 1 7}$ & & \\
BaA2-17-6 & Rhopalosiphum maidis & cv. Golden Promise \\
BaA2-17-7 & Sitobion avenae & cv. Kikai Hadaka \\
$\mathbf{2 0 1 8}$ & & \\
BaA3-18-8 & Rhopalosiphum maidis & OUK327 \\
BaA3-18-9 & Rhopalosiphum maidis & OUU094 \\
BaA3-18-10 & Rhopalosiphum maidis & pv. Minori Mugi \\
BaA3-18-11 & Rhopalosiphum maidis & cv. Minori Mugi \\
BaA3-18-12 & Rhopalosiphum maidis & cv. Kobin Katagi \\
BaA3-18-13 & Rhopalosiphum maidis & cv. Kobin Katagi \\
BaA3-18-14 & Rhopalosiphum maidis & cv. Ryofu \\
BaA3-18-15 & Rhopalosiphum maidis & cv. Golden Promise \\
\hline
\end{tabular}

${ }^{1}$ The species of the aphid colonies were identified by sequencing the nucleotides of fragments of a mitochondrial gene cytochrome $c$ oxidase 1 (COI) using RT-PCR. Rhopalosiphum padi (the bird cherry-oat aphid); R. maidis (the corn leaf aphid); Sitobion avenae (the English grain aphid). ${ }^{2}$ The five aphid samples (BaA3-18-10 to BaA3-18-14) were obtained from the barley plants grown in a different area of the IPSR field.

\section{Sequence Analysis and Database Search}

Open reading frames were identified using Enzyme X v3.3.3. Pairwise sequence comparisons were performed using the Sequence Demarcation Tool version 1.2, with the MUSCLE alignment (Muhire et al., 2014). The conserved protein domains were searched using the NCBI conserved domain database 4 . Putative transmembrane domains were predicted using the TMHMM server version $2.04^{5}$ (Krogh et al., 2001). Blast or reverse Blast searches were run on the non-redundant (nr) DNA and protein databases from NCBI (nucleotide collection, nr/nt; transcriptome shotgun assembly, TSA).

\section{Phylogenetic Analyses}

Maximum-likelihood (ML) tree construction was carried out as described previously with minor modifications (Kondo et al., 2015, 2016). Multiple amino acid alignments were obtained by using MAFFT online version $7^{6}$, set to the default parameters (Katoh and Standley, 2013). Ambiguous portions of the alignment were removed using Gblocks online version $0.91 \mathrm{~b}^{7}$ with the stringency levels lowered for all parameters (Talavera and Castresana, 2007). ML trees were then generated using the PhyML 3.0 online program ${ }^{8}$ with automatic model selection by Smart Model Selection (Guindon et al., 2010; Lefort et al., 2017). The NJ trees (Saitou and Nei, 1987) were constructed based on

\footnotetext{
${ }^{3}$ https://nucleobytes.com/enzymex/index.html

${ }^{4}$ https://www.ncbi.nlm.nih.gov/Structure/cdd/wrpsb.cgi

${ }^{5} \mathrm{http}: / /$ www.cbs.dtu.dk/services/TMHMM-2.0/

${ }^{6} \mathrm{http}: / /$ mafft.cbrc.jp/alignment/server/

${ }^{7}$ http://molevol.cmima.csic.es/castresana/Gblocks_server.html

${ }^{8}$ http://www.atgc-montpellier.fr/phyml-sms/
}

the multiple alignments using MAFFT. Then the phylogenetic trees were refined using FigTree version 1.3.1 software ${ }^{9}$.

\section{RESULTS AND DISCUSSION}

\section{Identification of Aphid Species Collected From the Barley Field}

In April and May in 2016-2018, we collected a total of 15 aphid population samples from the colonies on the barley plants that were grown in the experimental field of IPSR, Okayama (Table 1). Analysis of the mitochondrial COI sequence using genomic PCR and sequencing indicated that the aphid species collected were $R$. padi (the bird cherry-oat aphid), R. maidis (the corn leaf aphid), and S. avenae (the English grain aphid) (Table 1 and Supplementary Figure $\mathbf{S} 1$ and data not shown). R. maidis may be the predominant species of aphid populations in this barley field because $R$. maidis was obtained during each year of sampling and was also the main species collected of the aphid populations (10 out of 15 samples) (Table 1). Nevertheless, further intensive surveys are required to determine the actual aphid population and their dynamics in the field.

\section{Aphid Transcriptomic Analysis Using NGS}

To investigate the virome of these aphid samples, total RNA samples were pooled according to the year of sampling (pool-1 to pool-3) and subjected to transcriptomic analysis using NGS. The de novo assembled contigs that were larger than $1.0 \mathrm{~kb}$

\footnotetext{
${ }^{9} \mathrm{http}: / /$ tree.bio.ed.ac.uk/software/
} 
(pool-1: 10,133; pool-2: 15,562; and pool-3: 10,324 contigs) were subjected to local Blast (tBlastX) analyses (Figure 1A). Most of the contigs were associated with aphids (63-91\% contigs), with much fewer portions being associated with wasps (3-22\%) and endosymbionts ( 2 or $3 \%$ ). Aphid samples of the pool-1 might be highly parasitized by parasitoids (22\% contigs), such as $L$. testaceipes compared with those of other pools $(7 \%$ or $3 \%$ ) (Figure 1A and data not shown). Among the total contigs $(>1 \mathrm{~kb}$ ), at least 60 contigs (pool-1: $\sim 43$ contigs; pool-2: 5 contigs; and pool-3: 12 contigs) were virus-related sequences, with the length ranging from 1,102 to 23,141 nt (Figures 1A,B and see below). The proportions of sequence reads related to viral sequences largely differed among three libraries; $13 \%, 0 \%$, and $2 \%$ for pool-1, pool-2, and pool-3, respectively (Figure 1B).

\section{Identification of Virus-Related Sequences From the Aphid Transcriptomes}

Local Blast analyses revealed that the virus-like contigs present in the aphid transcriptomes have sequence similarity to relatives or members of the virus families, the Kitaviridae (or proposed Nelorpivirus and Sandewavirus), Flaviviridae, Tombusviridae, Phenuiviridae, Narnaviridae, Chrysoviridae,
Partitiviridae, Rhabdoviridae, and Luteoviridae (Figure 1B and Table 2). Notably, virus-like reads were predominantly mapped to virus-like contigs associated with nege/kitaviruses (25\%), flavi/jingmenviruses (49\%), and tombus-like virus (25\%) in pool-1; and nege/kitaviruses (39\%), flavi/jingmenviruses (35\%), and luteoviruses (26\%) in pool-3 (Figure 1B). The three luteovirus-like contig sequences in pools 1 and 3 are likely derived from plant viruses including barley yellow dwarf virus (a well-known luteovirus, family Luteoviridae). The detailed analysis of luteovirus, or luteo-like virus sequences identified in the current study will be reported elsewhere as a part of the ongoing barley virome project conducted in this barley field.

We performed RT-PCR to verify the presence of virusrelated RNAs in the aphid samples using the specific primer sets (Supplementary Table S1). The virus targets were successfully amplified from the aphid RNA samples (Supplementary Figures S2).

\section{Characterization of Nege/Kita-Like Virus Sequences}

We identified four contigs that resembled almost complete (coding complete) nege/kitavirus-like genome sequences (BaA1_c12; BaA3_c89; BaA3_c1889; and BaA3_c133,

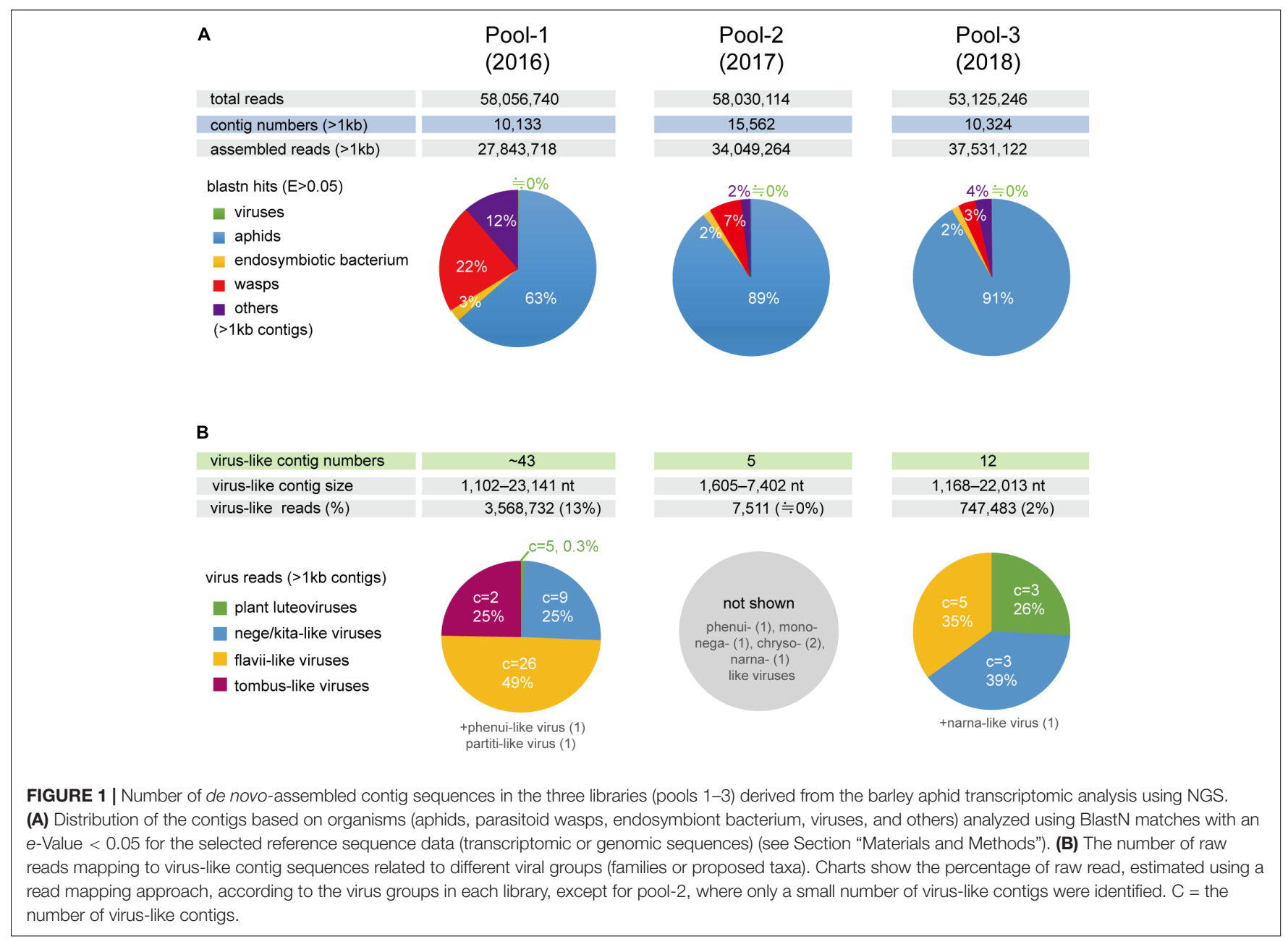


TABLE 2 | Major virus-like sequences from the barley aphid transcriptomes.

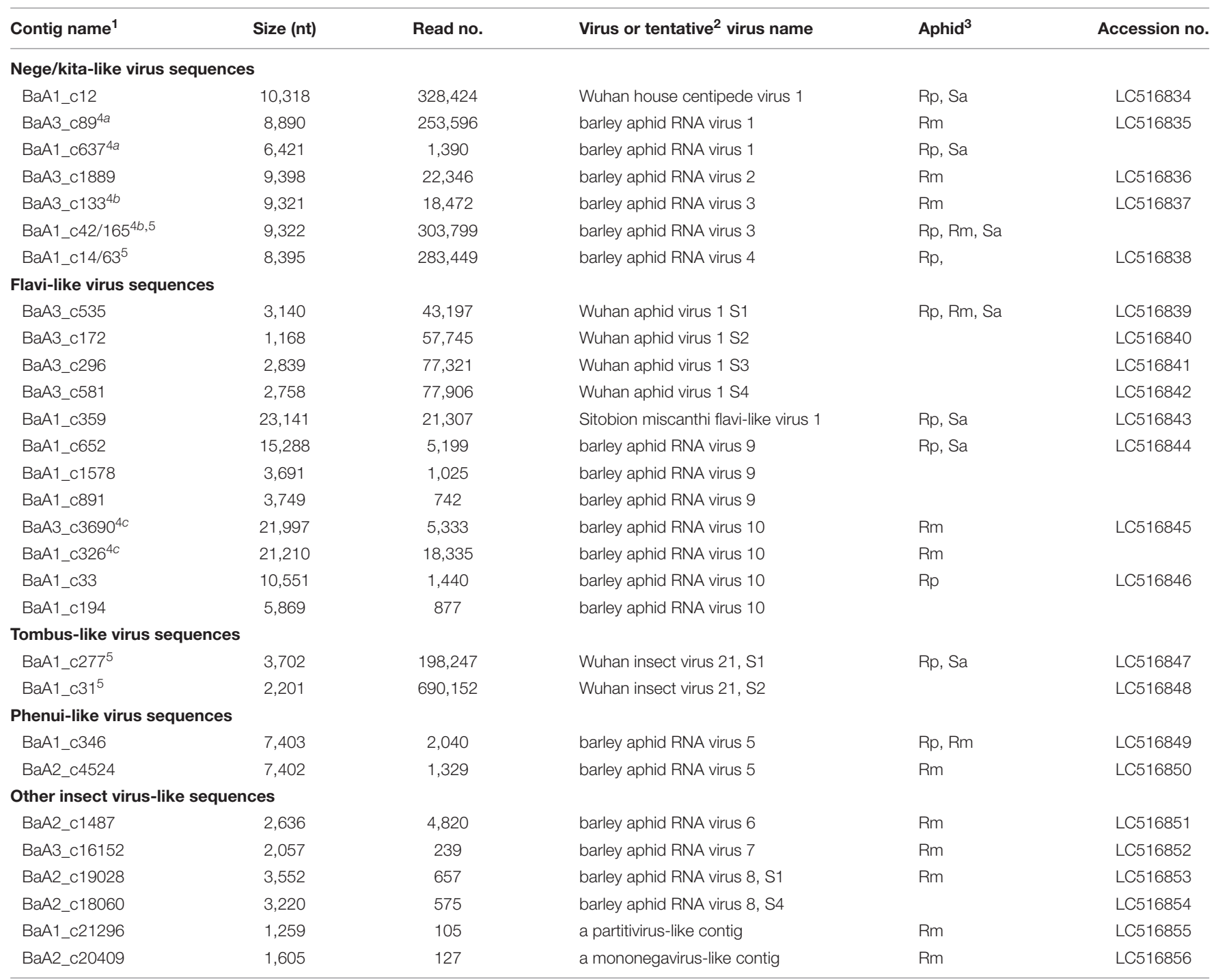

${ }^{1}$ Pool-1: BaA1; Pool-2: BaA2; Pool-3: BaA3. Some other variants of virus-like contigs are shown in Supplementary Figure S7, or not shown. Plant luteovirus-related sequences are not listed here. ${ }^{2}$ Nucleotide and/or amino acid sequence identity of the contig sequences are shown within Table 3 and Supplementary Table S4. Ten discovered novel viruses were designated as barley aphid RNA viruses 1 to 10 (see main text). S, RNA or dsRNA segment. ${ }^{3}$ Aphid species in discovery colonies assessed by RT-PCR detection (see Supplementary Figure S1A). Rp: Rhopalosiphum padi; Rm, R. maidis; Sa, Sitobion avenae. ${ }^{4}$ These sequences are slightly different from each other at the nucleic acid level ( ${ }^{4 a}: 3 \%,{ }^{4 b}: 1 \%$, and ${ }^{4 c}: 5 \%$ difference, respectively). ${ }^{5}$ The gap or unassembled regions were sequenced using RT-PCR (see Figure $2 D$ and Supplementary Figure S7C).

8,890-10,318 nt in length) with 18,472-328,424 mapped reads (Figure 2 and Table 1). Some other smaller fragments of nege/kitavirus-like sequences were also present in pools 1 and 3, but not in pool-2 (Figure 2 and Table 1). Each of the three sets of contigs, "BaA1_c42 and BaA1_c165," "BaA1_c14 and BaA1_c63," and "BaA1_c637," and "BaA1_c28720" are most likely derived from three different variants of a single viral strain, respectively (Figures 2B,D). RT-PCR and sequencing were carried out to determine their sequence gaps and, thus, semi-entire viruslike sequences were obtained (namely, BaA1_c42/165 and BaA1_c14/63, 9,322 and 8,395 nt with 303,799 and 283,449 mapped reads, respectively) (Figure 2D). In the case of contigs BaA1_c637 (1,390 reads) and BaA1_c28720 (210 reads), an attempt to connect their sequences using RT-PCR failed, possibly because of a very low level of virus titer in the samples (data not shown). These two newly assembled contigs derived from four above-mentioned virus-like sequences have large replicase-like ORFs (ORF1) followed by two putative structural protein genes for predicted glycoprotein and membrane protein SP24 (ORFs 2 and 3) (Kuchibhatla et al., 2014; Solovyev and Morozov, 2017), except for the BaA1_c12 contig, which has an additional small ORF in its $3^{\prime}$-proximal region, or the BaA1_c14/63 contig, which lacks the $3^{\prime}$-terminal region sequence (Shi et al., 2016a; Figure 2 and Supplementary Figures S3, S4).

The nucleotide sequence and encoded proteins of BaA1_c12 are almost identical (>99\% nucleotide and 99-100\% amino 
A Wuhan house centipede virus 1

strain arthropodmix13957 KX883740, $10310 \mathrm{nt}$

BaA1_c12 (328424 reads)

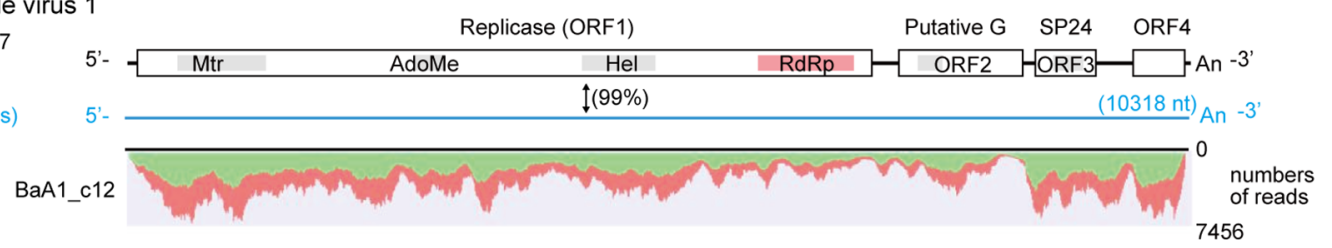

B Hubei virga-like virus 4 strain WHCCII13328 KX883814, $7920 \mathrm{nt}$

barley aphid RNA virus 1 BaA3_c89 (253596 reads) BaA1_c637 (1390 reads)

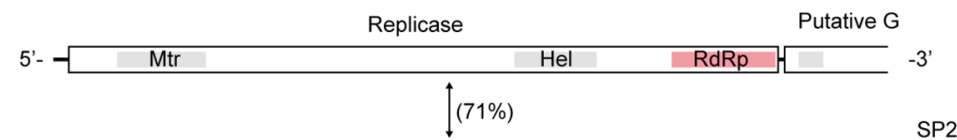

5'-

\begin{tabular}{|c|c|c|c|c|}
\hline Mtr & $\mathrm{Hel}$ & RdRp & $\square$ & - An -3' (8890 nt) \\
\hline & $\downarrow_{97 \%}$ & (6,421 nt) & $\uparrow 97 \%$ & BaA1 c28720 (210 reads \\
\hline
\end{tabular}

BaA3_c89

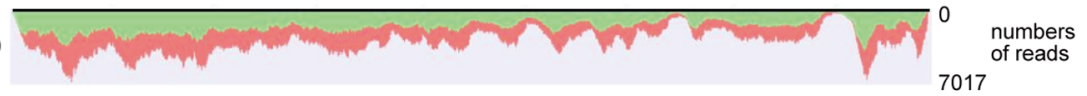

c

Wuhan insect virus 9

strain WHCCII13328

KX883816, $9305 \mathrm{nt}$

barley aphid RNA virus 2 BaA3_c1889 (22346 reads)

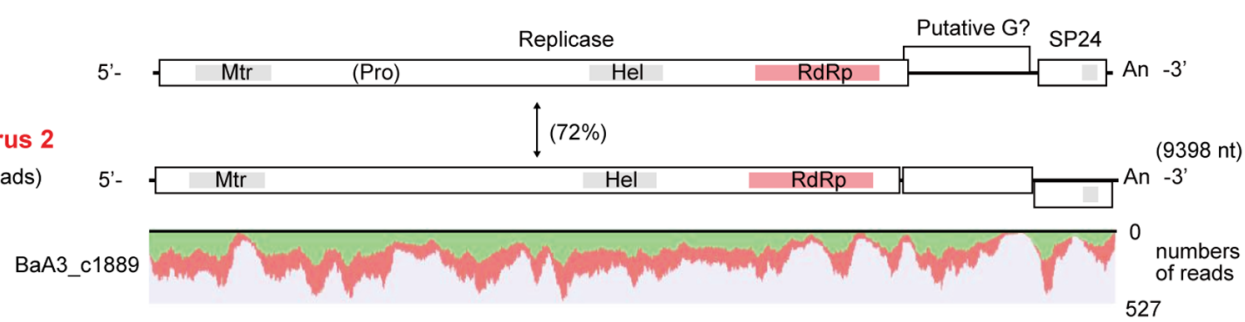

D barley aphid RNA virus 3 BaA3_c133 (18,472 reads) BaA1_c42/165 (303799 reads)
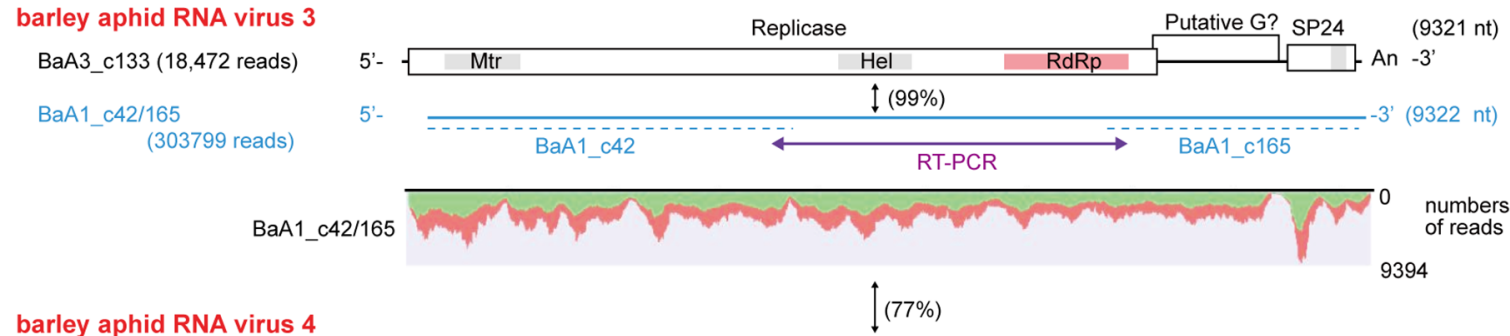

barley aphid RNA virus 4

BaA1_c14/63 (283449 reads)

5

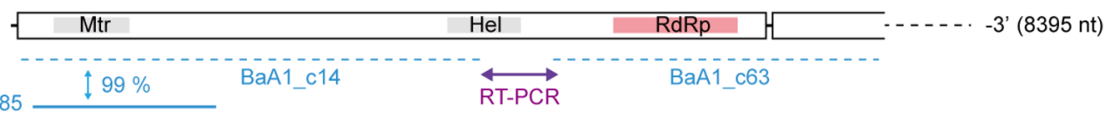
BaA1_c385

BaA1_c14/63

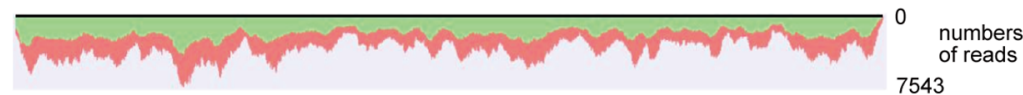

FIGURE 2 | Genome organization of nege/kita-like virus sequences identified from the transcriptomes of barley aphids, Rhopalosiphum padi; R. maidis, and Sitobion avenae. (A) Wuhan house centipede virus 1 genome. (B) Hubei nege-like virus 4 genome (a reference sequence lacking the $3^{\prime}$ terminal part) and a related novel aphid virus (named barley aphid RNA virus 1, BARV-1) (C) Wuhan insect virus 9 genome (a reference sequence) and the second novel aphid virus (named barley aphid RNA virus 2, BARV-2). (D) The third and fourth novel aphid viruses (named barley aphid RNA virus 3 and 4, BARV-3 and -4) genome. The open boxes in the genomic RNA represent open reading frames (ORFs). The conserved domains in viral replicase are shown (methyltransferase, Mtr; FtsJ-like RNA ribosomal methyltransferase, AdoMet/FtsJ; RNA helicase, HEL; RNA-dependent RNA polymerase, RdRp). Other putative conserved domains (putative glycoprotein and SP24 protein) are indicated as gray highlights within the ORFs. Virus-like contigs identified from this study are shown as blue bars or blue lines. The sequence gaps between the two contigs for BARV-3 (BaA1_c42 and BaA1_c165) and BARV-4 (BaA1_c14 and BaA1_c63) were determined using RT-PCR and sequencing. The nucleotide sequence identities between a reference virus and a virus-like contig are shown in parentheses with black color. The nucleotide sequence identities between two virus-like contigs are shown in blue color with no parentheses. Read depth coverage throughout the assembled virus-like contigs together with two gap-filling virus-like sequences determined using RT-PCR (BaA3_c42/165 and BaA1_c14/63) is presented below the schematic structures of the viral genomes. The Y-axis shows the mapping-read coverage with the maximum read depth (read number) on each virus-like sequence. Green and red colors indicate positive and negative strand of sequence reads, respectively. 
acid identities) to those of the Wuhan house centipede virus 1 (WHCV-1) (Supplementary Table S3), suggesting that the BaA1_c12 sequence is derived from a strain of WHCV-1, infecting two aphid species ( $R$. padi and $S$. avenae) that infested barley plants. The two contigs BaA3_c89 and BaA1_c637 (lacking 3 -terminal region sequence) showed 97\% nucleotide identity with each other and $71 \%$ nucleotide identity with Hubei virga-like virus 4 (HVLV-4) (Figure 2B and Table 3). A BlastP search revealed that the two contigs share moderate levels of amino acid sequence identity (45-58\%) with HVLV-4 (Table 3). Although taxonomic criteria for species demarcation have not been established for nege-like viruses, both of the two HVLV-4-like sequences most likely represent a novel nege/kitalike virus that infects $R$. padi and S. avenae (BaA1_c637) or $R$. maidis (BaA3_c89) [our tentative cut-off value for the species classification criteria for nege-like viruses is $<90 \%$ amino acid identities of RNA-dependent RNA polymerase (RdRp) sequences], rather than being a strain of HVLV-4; therefore we tentatively designated the virus as barley aphid RNA virus 1 (BARV-1).

Contig BaA3_c1889, derived from R. maidis, appeared to be a novel nege/kita-like virus related to Wuhan insect virus 9 (WhIV-9) because they share moderate levels of identities at the nucleotide $(72 \%)$ and amino acid $(66 \%-80 \%)$ sequence
(Tables 2 and 3). We named this putative nege/kita-like virus as barley aphid RNA virus 2 (BARV-2). Two contigs, BaA3_c133 and BaA1_c14/63 (lacking 3 '-terminal region sequence), together with BaA1_c42/165 (almost identical to the BaA3_c133 contig) also showed similar levels of nucleotide identity (72\%) with WhIV-9 and its relatives, Hubei Wuhan insect virus 9 (HWIV-9) (Table 3). Their proteins showed lower levels of amino acid sequence identity $(41 \%-58 \%)$ than those of the BaA3_c1889 contig (Table 3). In addition, they shared 77\% nucleotide and $69 \%$ amino acid sequence identities between each other. Thus, contigs BaA3_c133 and BaA1_c42/165, and BaA1_c14/63 appear to represent two novel nege/kita-like viruses, which we tentatively designated as barley aphid RNA virus 3 and 4 (BARV-3 and -4), and it associated with $R$. padi (BaA1_c14/63, BARV-4); R. maidis (BaA3_c133, BARV-3); or R. padi, R. maidis, and S. avenae (BaA1_c42/165, BARV-3) (Table 2 and Supplementary Figure S2A).

\section{Search for Nege/Kita-Like Virus Sequences Using the TSA Database}

Recently, the presence of several nege/kita-like viruses and related virus-like sequences, has been reported from invertebrate meta-transcriptome analyses or surveys of insect transcriptomic

TABLE 3 | Nege/kita-like virus sequences identified from the barley aphid transcriptomes using Blast search.

\begin{tabular}{|c|c|c|c|c|c|}
\hline Query contig & Top hit virus & $Q C^{1}$ & $E$-value & identify & Accession \\
\hline \multicolumn{6}{|c|}{ BlastN search (discontiguous megablast) } \\
\hline \multicolumn{6}{|c|}{ Query sequence: entire nucleotide sequences } \\
\hline BaA1_c12 & Wuhan house centipede virus 1 & $99 \%$ & 0.0 & $99 \%$ & KX883740 \\
\hline BaA3_c89 & Hubei virga-like virus 4 & $52 \%$ & 0.0 & $71 \%$ & KX883814 \\
\hline BaA3_c1889 & Wuhan insect virus 9 & $99 \%$ & 0.0 & $72 \%$ & KX883816 \\
\hline BaA1_c42/165 & Wuhan insect virus 9 & $53 \%$ & 0.0 & $72 \%$ & KX883816 \\
\hline BaA1_c14/63 & Hubei Wuhan insect virus 9 & $54 \%$ & 0.0 & $73 \%$ & KX883782 \\
\hline \multicolumn{6}{|l|}{ BlastP search } \\
\hline \multicolumn{6}{|c|}{ Query sequence: RdRp } \\
\hline BaA1_c12 & Wuhan house centipede virus 1 & $99 \%$ & 0.0 & $99 \%$ & APG77795 \\
\hline BaA3_c89 & Hubei virga-like virus 4 & $52 \%$ & 0.0 & $58 \%$ & APG77770 \\
\hline BaA3_c1889 & Wuhan insect virus 9 & $98 \%$ & 0.0 & $78 \%$ & APG77775 \\
\hline BaA3_c133 & Wuhan insect virus 9 & $53 \%$ & 0.0 & $57 \%$ & APG77775 \\
\hline BaA1_c14/63 & Hubei Wuhan insect virus 9 & $54 \%$ & 0.0 & $58 \%$ & APG77665 \\
\hline \multicolumn{6}{|c|}{ Query sequence: p2 (putative glycoprotein) } \\
\hline BaA1_c12 & Wuhan house centipede virus 1 & $99 \%$ & 0.0 & $99 \%$ & APG77796 \\
\hline BaA3_c89 & Hubei virga-like virus 4 & $77 \%$ & $2 e-112$ & $50 \%$ & APG77771 \\
\hline BaA3_c1889 & Wuhan insect virus 9 & $96 \%$ & 0.0 & $66 \%$ & APG77776 \\
\hline BaA3_c133 & Wuhan insect virus $9^{2}$ & $87 \%$ & $3 e-86$ & $41 \%$ & APG77776 \\
\hline BaA1_c14/634 & Wuhan insect virus $9^{2}$ & $91 \%$ & $1 e-92$ & $48 \%$ & APG77776 \\
\hline \multicolumn{6}{|c|}{ Query sequence: p3 (SP24 family) } \\
\hline BaA1_c12 & Wuhan house centipede virus 1 & $99 \%$ & $4 e-139$ & $100 \%$ & APG77797 \\
\hline BaA3_c89 & Wuhan house centipede virus 1 & $69 \%$ & $3 e-46$ & $45 \%$ & APG77797 \\
\hline BaA3_c1889 & Hubei Wuhan insect virus 9 & $90 \%$ & $5 e-117$ & $80 \%$ & APG77670 \\
\hline BaA13_c133 & Hubei Wuhan insect virus $9^{2}$ & $98 \%$ & $3 e-68$ & $52 \%$ & APG77670 \\
\hline BaA1_c14/63 & not available & & & & \\
\hline
\end{tabular}

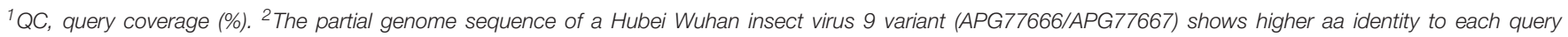
sequence (59\%-85\%) (see Supplementary Figures S4B-E). 
datasets (Shi et al., 2016a; Kondo et al., 2019). To further explore the presence of unknown nege/kitavirus-like sequences, we conducted tBlastN searches against publicly available TSA datasets using BARV-1 and BARV-2 sequences as queries. The search identified several TSA sequences derived from hemipteran, hymenopteran, and dipteran species with a few plant species that represent nearly complete (>9.0 kb lengths) or partial viral genome sequences (Supplementary Table S2 and data not shown). Two plant TAS sequences from a tree species, Paulownia tomentosa (family Paulowniaceae) (Fan et al., 2016), most likely represented the segments of a novel RNA virus belonging to the blunervirus-lineage (Supplementary Table S2 and also see Figure 3).

\section{Phylogenetic Relationships Among Nege/Kita- and Nege/Kita-Like Viruses}

To understand the relationships between newly discovered nege/kita-like viruses, viral-like TSAs and reported nege/kitaviruses, we conducted ML phylogenetic analysis based on amino acid alignment of their replicase and replicaselike sequences. The ML tree showed that the BARV-1 variants clustered with HVLV-4 and its relatives, WHCV-1 and Wuhan insect virus 8 (WhIV-8) (referred to as "group 1"); whereas the BARV-2, -3 , and -4 form a well-supported clade with the relatives of WhIV-9, and HWhIV-9, and ApGIV-3 from Aphis glycines (the soybean aphid) (referred to as "group 2") (Figure 3). These two virus groups together with other nege/kita-like viruses and arthropod virus-like TSAs, fill the phylogenetic gaps between negevirus-related (nelorpiviruses and sandewaviruses) and kitavirus-related (cile/higreviruses and blunerviruses) lineages (Vasilakis et al., 2013; Kallies et al., 2014; Nunes et al., 2017; Figure 3 and Supplementary Table S2). Our phylogenetic analysis, thus, suggests that novel groups 1 and 2 of nege/kita-like viruses including aphid-infecting viruses belong to two new distinct genera, tentatively designated as "Centivirus" (after Wuhan house centipede virus 1) and "Aphiglyvirus" (after Aphis glycines virus 3), respectively. Members of these two proposed genera, together with two proposed taxa of arthropod-restrictive viruses, "Nelorpivirus" and "Sandewavirus," which all have non-segmented genomes, could be classified into a novel viral family or be assigned to the family Kitaviridae. However, it is to too early to establish a family for these viruses or to assign them into the Kitaviridae, because there is no reliable statistical support for these lineages within the currently available phylogenetic trees (Kallies et al., 2014; Nunes et al., 2017; Kondo et al., 2019; Ramos-González et al., 2020; Figure 3). The result of molecular phylogenetics indicate that the two major lineages of kitaviruses (cile/higreviruses and bulunerviruses) are not monophyletic, which all have two or multi-segmented RNA genomes and separately encode their replicase (RdRp) and SP24 family protein on the different segments (Locali-Fabris et al., 2006; Melzer et al., 2013; Hao et al., 2018), suggesting that genome segmentation possibly occurred independently during the evolution of kitaviruses. As previously proposed for plant rhabdoviruses (Kondo et al., 2017), the genome segmentation event may be associated with the vector mites (Brevipalpus spp.), at least in the case of the cile/higreviruses lineage.

\section{Host Ranges and Spread of Nege/Kita-Like Viruses}

WHCV-1 (a centivirus) was identified from the house centipede (Scutigeridae sp., phylum Arthropoda) and also from three other arthropods, spiders, and insects (WHCCII, insect mix 4) (Shi et al., 2016a). Because the last sample WHCCII included two aphid species (Hyalopterus pruni and Aulacorthum magnolia), a parasitoid wasp (Aphelinus sp., Hymenoptera), and some other insects such as dipterans, an orthopteran, and a coleopteran (Shi et al., 2016a), WHCV-1 may have a wide host range within arthropods (centipedes, spiders, and insects, including aphids as described in this study). Other centiviruses, WhIV8 and HVLV-4, were also identified from the same insect pool (WHCCII) along with WhIV-9 (an aphiglyvirus), but their insect host ranges are still uncertain (Shi et al., 2016a). WHCV-1 and the two novel viruses, BARV-1 and BARV-3, were detected in four aphid colonies from the 2016 sample (WHCV-1 and BARV-1) or six aphid colonies from both 2016 and 2018 samples (BARV-3); whereas other viruses or variants were detected in a single aphid colony from the 2016 (BARV-4) and 2018 samples (BARV-2) (Supplementary Figure S2A). Notably, WHCV-1 and BARV-3 were detected in three different aphid species, R. padi, R. maidis and $S$. avenae collected in 2016 (Supplementary Figure S2A). Intriguingly, our preliminarily results showed the presence of these aphid virus-related sequences in the barley plant samples from the same field in the same year (HK and MF unpublishded results). Therefore, barley and/or other plants may potentially reserve aphid viruses and facilitate the horizontal transmission of the viruses among aphid populations, similarly to what was reported previously for an aphid picornavirus (RhPV) (Gildow and Darcy, 1988; Ban et al., 2007). WHCV-1-, BARV-3- and BARV-4-related sequences were identified in the TSA datasets derived from the Polish wheat (Triticum polonicum) (Supplementary Figure S5). WhIV-8- and BARV-2-like sequences were found in an allopolyploid bean species (Glycine dolichocarpa, Fabaceae) or the pomegranate (Punica granatum, Lythraceae) (Supplementary Figure S5 and Supplementary Table S2), and some insectspecific viruses (densoviruses and dicistroviruses) have also been found from plant materials, such as cucumber, bean, Brassica oleracea, red cestrum (Solanaceae), maize and sea barley (van Munster et al., 2005; François et al., 2014; Maina et al., 2017; Wamonje et al., 2017; Roumi et al., 2020). Thus, these findings support the notion that plants serve as passive vectors for the transmission of aphid viruses.

WhIV-9, an aphiglyvirus from the WHCCII insect pool, has been identified from a dragonfly (Odonata sp., order Odonata) (Shi et al., 2016a), whereas WhIV-9-like TSA sequences was also found in $D$. carpenter, an aphid hyperparasitoid wasp (Figure 3 and Supplementary Table S4). The presence of WhIV-9-like sequences in the hyperparasitoid wasp may suggest that the virus could be horizontally transmitted between this wasp and an aphid host through a primary parasitoid. In cereal aphids, 


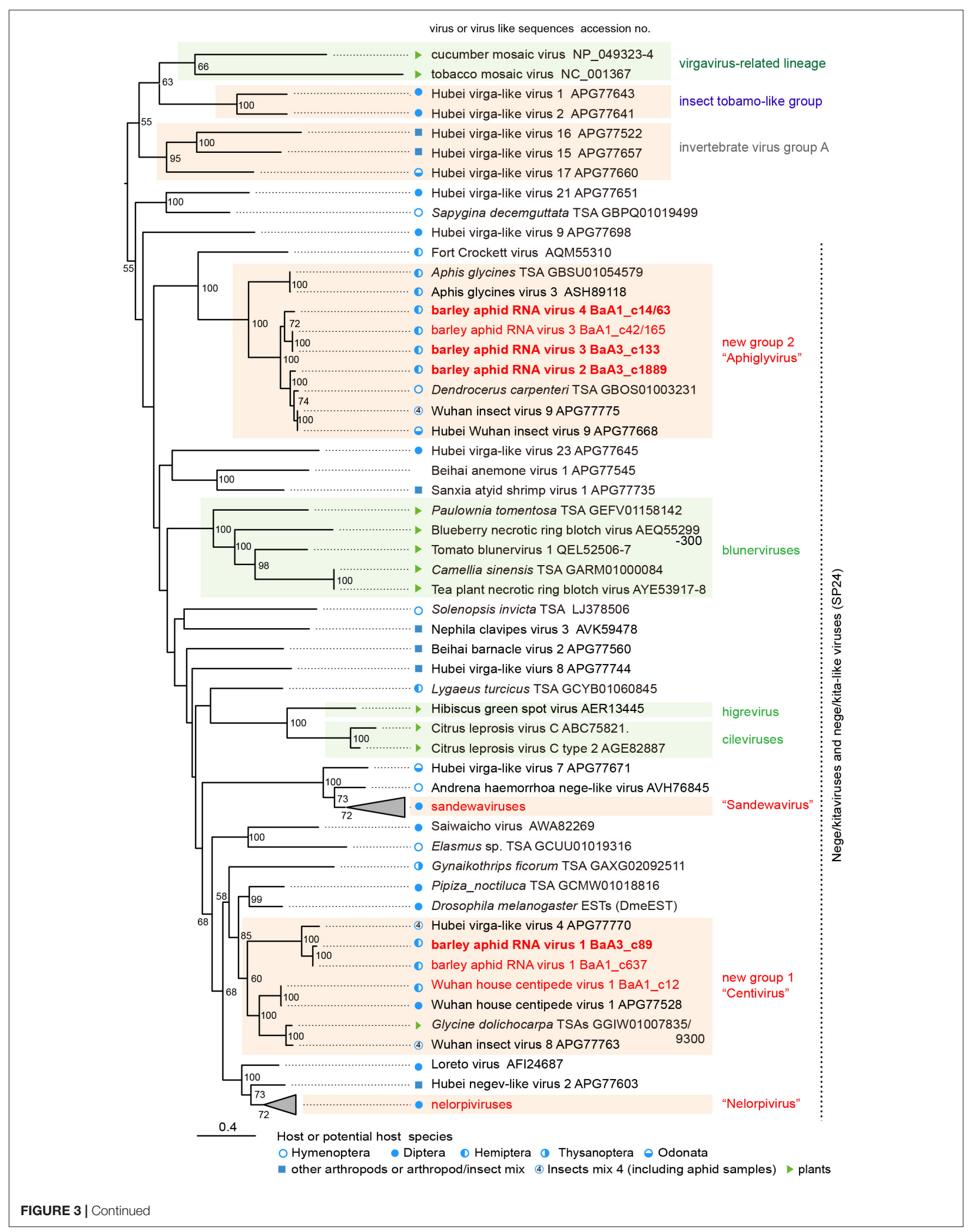


FIGURE 3 | Phylogenetic relationships of the nega/kitaviruses and their related viruses and other virus-like sequences. The maximum likelihood (ML) phylogenetic tree was constructed using PhyML 3.0 based on a multiple amino acid sequence alignment of the replicase protein or its candidate sequences. A model $L G+I+G+F$ was selected as a best-fit model for the alignment. The tree was rooted using the midpoint rooting method. Virus names referring to plant-infecting viruses (genera Cilevirus, Higrevirus, and Blunervirus, family Kitaviridae) and insect-infecting or associated viruses are followed by the GenBank accession numbers of their sequences. The selected members of the proposed groups "Sandewavirus" and "Nelorpivirus" are displayed as collapsed triangles (see Supplementary Table S3 for the virus names in the collapsed triangles). Nege/kitavirus-like transcriptome shotgun assembly (TSA) sequences, discovered by this study (see Supplementary Table S2) or our previous study (Kondo et al., 2019), were also included in this analysis. A library of insect mixtures (WHCCII, insect virus 4) for the meta-transcriptomic analysis included two aphid species, a parasitoid wasp, and several other insects (Shi et al., 2016a). The hosts, or possible hosts, for nege/kitaviruses or virus-like sequences present in TSAs are marked with symbols (circles, squares, and triangles, respectively). Vertical dashed lines indicate that most of those viruses or virus-like sequences potentially encode conserved small proteins (SP24 family) (Kuchibhatla et al., 2014). The selected members of distantly related virus lineage, belonging to the plant virgavirus-related lineage (tobacco mosaic and cucumber mosaic viruses), insect tobamo-like virus group (Hubel virga-like viruses 1 and 2), and invertebrate virus group A (Hubel virga-like viruses 15, 16, and 17) (Kondo et al., 2019), were used as the outgroups. The scale bar represents amino acid distances. The numbers at the nodes are bootstrap values of $>50 \%$.

such as $S$. avenae, the attack of hyperparasitoids against primary parasitoids has been observed in the field (Holler et al., 1993). In our meta-transcriptome analyses, some aphid populations might be infected with the primary parasitoids, although it is still unknown whether the hyperparasitoids are also present in the IPSR field (Supplementary Figure S2A). A primary parasitoid (L. testaceipes), but not a secondary parasitoid (D. carpenteri), was detected in the aphid samples using RTPCR (Supplementary Figure S6). It has been reported that an RNA virus, Lysiphlebus fabarum virus, related to BrBV (an aphid iflavirus), was found in an aphid parasitoid wasp (Lysiphlebus fabarum) (Lüthi et al., 2019). Its closest related virus, Venturia canescens picorna-like virus, replicates in both a parasitoid wasp and a lepidopteran host (Reineke and Asgari, 2005). An aphid picornavirus ALPV has been detected in the honey bees and its predator hornet Vespa velutina (Hymenoptera) (Granberg et al., 2013; Yang et al., 2019). Therefore, further studies are necessary to understand the dynamics and spread of nege/kita-like viruses among barley aphid populations, including their parasitoid and hyperparasitoid hymenopterans.

\section{Characterization of Flavi-Like Virus Sequences}

In addition to the nege/kita-like viruses (centi- and aphiglyviruses), we identified several contigs related to other RNA viruses, such as flavi/jingmen- and tombus-like virus sequences (Figure 1 and Table 2). WhAV-1, a jingmenvirus, which belongs to a recently identified group of the foursegmented RNA viruses related to unsegmented flaviviruses (Shi et al., 2016b; Temmam et al., 2019), was one of the major constituents of flavi/jingmenvirus-like reads (Figure $\mathbf{1}$ and Table 2). Sequence homology analyses suggest that at least three variants of WhAV-1 (1a, 1b, and 1c variants) were associated with barley aphids (Supplementary Figure S7A and Supplementary Table S4). The "1b" variant of WhAV-1 (the BaA3_c535 contig and some others), which is related to the reference viral sequence sharing $\sim 87 \%$ nucleotide and $\sim 95 \%$ amino acid sequence identities, was found in five aphids colonies containing all three species from the 2016 sample and $R$. maidis from the 2018 sample (Supplementary Figure S2B). In contrast, the " $1 \mathrm{a}$ " (the BaA1_c139 contig) and " $1 \mathrm{c}$ " (the BaA1_c13 contig) variants, which are related to the reference sequence sharing $91 \%$ and $78 \%$ nucleotide and $92 \%$ and $87 \%$ amino acid sequence identities, were only detected in an R. padi colony from the 2016 sample (BaA1_c139) and in two aphid colonies ( $R$. padi and $R$. maidis) from the 2016 sample (BaA1_c13), respectively (Supplementary Figure S2B and data not shown). WhAV-1b sequences (BaA3_c535, c172, c296, and c581 for RNA segments 1-4) have been deposited into the DDBJ data bank as a representative genome sequence (Table 2). In the phylogenetic tree, based on the non-structural protein NSP1 (NS5-like, RdRp) encoded in segment 1, jingmenviruses are divided into two different clades; the WhAV-1 variants and a second aphid-associated jingmenvirus, WhAV-2, form a subclade within the clade consisting of insect and some other arthropod jingmenviruses; whereas the second clade contains jingmenviruses infecting ticks (class Arachnida), such as jingmen tick virus, which may be a novel tick-borne arbovirus that infects humans and other mammals (Jia et al., 2019; Supplementary Figure S7B). WhAV-1 sequences were identified in the aphid-free barley samples as mentioned above (HK and MF unpublishded results), and interestingly, a variant of WhAV-2 was found in a pea plant transcriptome (Pisum sativum, accessions MK948535-8, deposited by Y.Z.A. Gaafar and H. Ziebell) (Supplementary Figure S2B and Supplementary Table S2), raising a speculation that jingmenviruses that infect aphids may have been horizontally transmitted among aphid populations, with plants as the reservoirs (Gildow and Darcy, 1988; Ban et al., 2007).

Another type of flavivirus-like sequences seems to be the minor populations among aphid flavi-related viruses (Table 2). The BaA1_c359 contig is derived from a variant Sitobion miscanthi flavi-like virus 1 (SmFLV-1, MH778148 deposited by T. Li), showing $92 \%$ nucleotide and $98 \%$ amino acid sequence identities (Supplementary Table S4). The BaA1_c652 contig (probably together with BaA1_c1578 and c891 contigs) sharing $73 \%$ nucleotide and $62 \%$ amino acid sequence identities with that of MeV-1 from European M. euphorbiae populations (Teixeira et al., 2016) and the BaA3_c3690 together with its two variants BaA1_c326 and c33 (a partial sequence) contigs showing 67$68 \%$ nucleotide and $44-59 \%$ amino acid sequence identities with that of SmFLV-1, are likely to represent two novel flavilike viruses. Thus, we tentatively named barley aphid RNA virus 9 (BARV-9) and barley aphid RNA virus 10 (BARV10) (Figure $\mathbf{4 A}$ and Table 2 ). The complete coding sequence 
A

Sitobion miscanthi flavi-like virus 1 MH778148

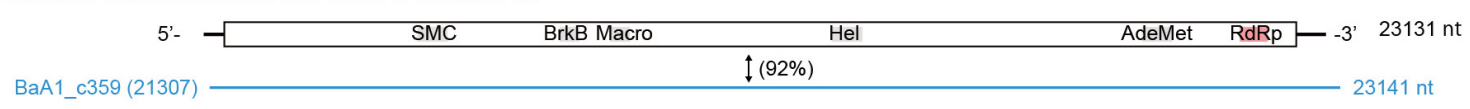

Macrosiphum euphorbiae virus 1 KT309079

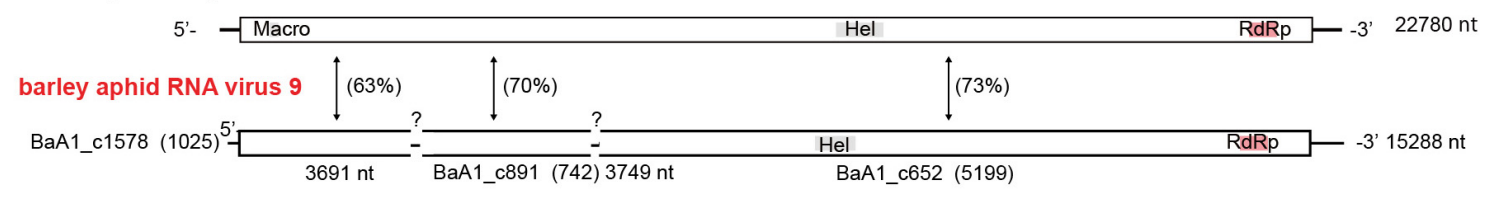

barley aphid RNA virus 10

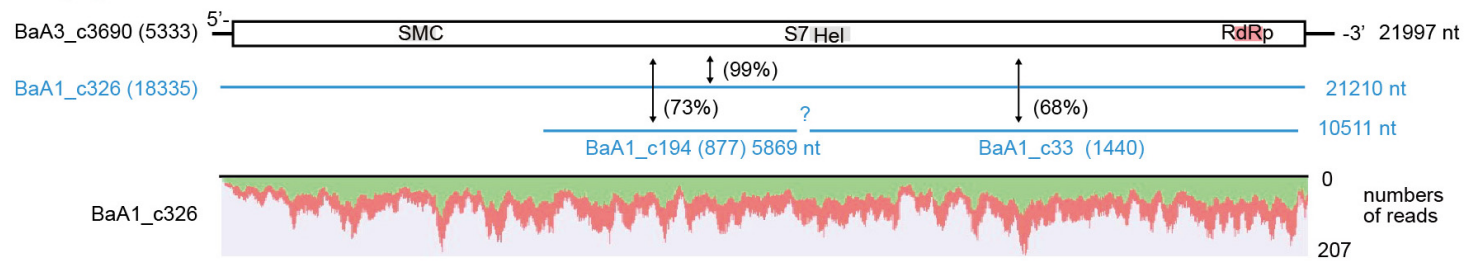

B

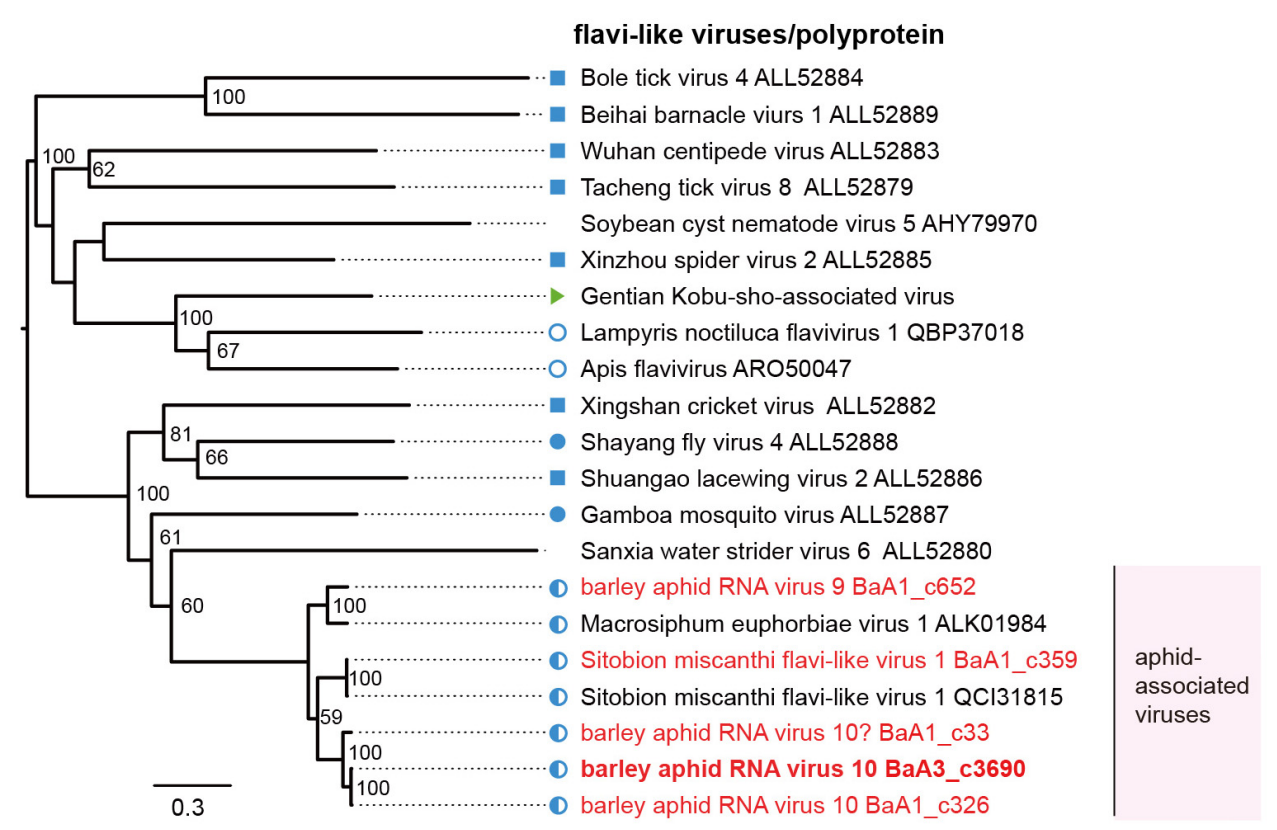

Host or potential host species

O Hymenoptera Diptera O Hemiptera other arthropods or arthropod/insect mix plants

FIGURE 4 | Genome organizations and phylogenetic relationships of flavi-like viruses. (A) The genome structures of flavi-like viruses, Sitobion miscanthi flavi-like virus 1, Macrosiphum euphorbiae virus 1, and two novel flavi-like viruses (named barley aphid RNA virus 9 and 10, BARV-9 and -10) from Rhopalosiphum padi, R. maidis, and Sitobion avenae. Conserved domains for viral polyproteins or other proteins are shown as gray or red highlights within the ORFs (Macro domain, a high-affinity ADP-ribose binding module; SMC super family, chromosome segregation ATPase; BrkB, This family may act as a virulence factor; S7, Flavivirus NS3 serine protease; HEL, RNA helicase; AdoMet, S-adenosylmethionine-dependent methyltransferases; RdRp, RNA-dependent RNA polymerase). Virus-like contigs derived from this study are represented as black bars or blue lines and other information is the same as shown in Figure $\mathbf{2}$. Read depth coverage throughout the assembled virus contig is shown below the schematic structure of the viral genome. (B) Phylogenetic relationships of flavi-like viruses. The ML phylogenetic tree was constructed using a multiple amino acid sequence alignment of the polyprotein or its candidate sequences. The scale bar represents amino acid distances. The numbers at the nodes are bootstrap values of $>50 \%$. 
of BARV-3 (BaA3_c3690) is 21,997 nt in length, similar to the genomes of MeV1 (22,780 nt) and SmFLV-1 (23,131 nt) (Figure 4A). The single large ORF of BARV-9 encodes a putative polyprotein of 7,081 amino acids, containing putative helicase, NS3 serine protease, and RdRp motifs, but not the motifs predicted for structural proteins and methyltransferase (Figure 4A). In the phylogenetic tree based on polyproteins (Figure 4B), aphid-associated flavi-like viruses form a clade and clustered with some invertebrate flavi-like viruses, whereas its sister clade contains several invertebrate flavi-like viruses and a plant virus, Gentian Kobu-sho-associated virus (Kobayashi et al., 2013; Bekal et al., 2014; Shi et al., 2016b; Remnant et al., 2017), that still have an uncertain taxonomic status. SmFLV-1 and BARV-9 variants were found in two aphid colonies (R. padi and $S$. avenae) from the 2016 sample and SmFLV-1 probably also in a $R$. maidis colony from the 2018 sample in which low levels of viral RNA accumulation was detected using RTPCR, whereas no virus reads were found in the NGS data, thus expanding its aphid host range. BARV-9-like TSA sequences were also found in S. avenae (Supplementary Figure S5). BARV-10 variants were detected in two $R$. maidis colonies from the 2016 and 2018 samples (BaA1_c326) or an $R$. padi colony from the 2016 sample (BaA1_c33) (Supplementary Figure S2B). Similar to the nege/kita-like viruses, multiple flavi-like viruses belonging to at least three viruses (BARV-9, BARV-10 and SmFLV-1) were present in barley aphid populations that infest the IPSR field; however, their prevalence in the aphid populations seems to be much lower than that of nege/kita-like viruses and a jingmenvirus (WhAV-1) (Table 2 and Supplementary Figure S2).

\section{Characterization of Tombus-Like Virus Sequences}

Recently, the diversity of the tombusvirus-like lineage has been greatly expanded by the discovery of a large number of tombuslike viruses from invertebrates (Shi et al., 2016a). One of these viruses, Wuhan insect virus 21 (WhIV-21), was detected in the WHCCII insect pool; the same pool in which the above mentioned viruses were detected. In this study, we found a variant of WhIV-21 (BaR1_c277 and c31 contigs, sharing 83\% and $73 \%$ nucleotide and $90 \%$ and $50 \%$ amino acid sequence identities with WhIV-21) in $R$. padi and $S$. avenae aphids from the 2016 sample, but not from R. maidis (Table 2, Supplementary Figure S2B, and Supplementary Table S4). The complete coding sequences of WhIV-21 were verified using RT-PCR and sequencing (Supplementary Figure S7C). The read numbers of WhIV-21 (198,247 reads for BaR1_c277, and 690,152 reads for BaR1_c31), whose sequences were also detected in the barley samples (HK and MF unpublishded results), were higher than those of jinmenviruses and similar to some nege/kitaviruses (Table 2). The ML phylogenetic tree, based on RdRp sequences encoded by the RNA1 segments, showed that WhIV-21 is clustered with a bee pathogen, Chronic bee paralysis virus (CBPV, proposed genus "Chroparavirus"), and several invertebrate tombus-like viruses (Shi et al., 2016a; Bigot et al., 2017; Supplementary Figure S7D). Similar to CBPV, which may form a ellipsoidal virion, the WhIV-21 RNA2 segment seems to encode two proteins; a putative virion glycoprotein and SP24 homolog that probably have features of the major structural components, similar to what was previously proposed for CBPV and some negeviruses (Kuchibhatla et al., 2014; Solovyev and Morozov, 2017).

\section{Characterization of Other Novel Aphid-Associated Virus Sequences}

Two negative-sense RNA virus-like sequences (BaA1_c346 and BaA2_c4524, both minor read numbers within the data set) represent phenuiviruses (family Phenuiviridae) (Figure 5A and Table 2). These two sequences are closely related to each other (82\% nucleotide and 94\% amino acid sequence identities) and their encoded proteins (2,344 or 2,345 amino acids) are distantly related to $\mathrm{L}$ proteins ( $\mathrm{RdRp}$ ) of phenui-like viruses, such as Hubei bunya-like virus 2 from a dragonfly (35\% amino acid sequence identity) (Shi et al., 2016a; Supplementary Table S4). We tentatively named this potentially novel virus as barley aphid RNA virus 5 (BARV-5). The BaA1_c346 related sequences were detected in all aphid colonies ( $R$. padi, R. maidis and probably $S$. avenae) from the 2016 sample, whereas the BaA2_c4524 sequence was only detected in $R$. maidis aphids from the 2017 sample (Supplementary Figure S2B). In the phylogenetic tree, based on L proteins, BARV-5 was clustered with some invertebrate phenui-like viruses that will probably be classified as the members of a novel genus (or genera). A neighboring clade consisted of recently discovered phenui-like viruses that have bi- or tripartite RNA genomes and are associated with plants, fungi, and invertebrates, belonging to the proposed viral genera (Navarro et al., 2018; Tokarz et al., 2018; Lin et al., 2019; Figure 6B). Similar to these phenui-like viruses, BARV5 may also have additional RNA segment(s) encoding other viral proteins, such as the nucleocapsid protein. In addition to the phenui-like virus, one negative-sense mononega-like virus sequence (BaA2_c20409, a $1.6 \mathrm{~kb}$ fragment) was detected in R. maidis aphids from the 2017 sample (Table 2 and Supplementary Figure S2B). This contig sequence showed a moderate level of sequence similarity ( $40 \%$ amino acid identity) with the $\mathrm{L}$ protein of Linepithema humile rhabdo-like virus from the queen samples of the Argentine ant (Linepithema humile) (Viljakainen et al., 2018; Supplementary Table S4) and forms a clade of unassigned non-segmented RNA viruses (order Mononegavirales), together with Hubei rhabdo-like virus 3 and Tacheng tick virus 6 (Shi et al., 2016a) (data not shown).

Two positive sense RNA virus-like sequences (BaA2_c1487 and $\mathrm{BaA} 3$ _c16152) were identified in $R$. maidis aphids from the 2017 sample (BaA2_c1487, a complete coding $2.6 \mathrm{~kb}$ sequence) and the 2018 sample (BaA3_c16152, a fragment of $2.0 \mathrm{~kb}$ ) (Table 2, Figure 6A and Supplementary Figures S2B). Both sequences potentially encoded an $\mathrm{RdRp}$ related to that of a narna-like virus (Aedes angustivittatus narnavirus) sharing 34\% (BaA2_c1487) or 30\% (BaA3_c16152) amino acid sequence identities (Fauver et al., 2019; Supplementary Table S4). We named these two putative narna-like viruses as barley aphid RNA virus 6 and 7 (BARV-6 and -7). Although the BaA3_c16152 contig lacks terminal region sequences, BARV-7 may have a genome 
A barley aphid RNA virus 5

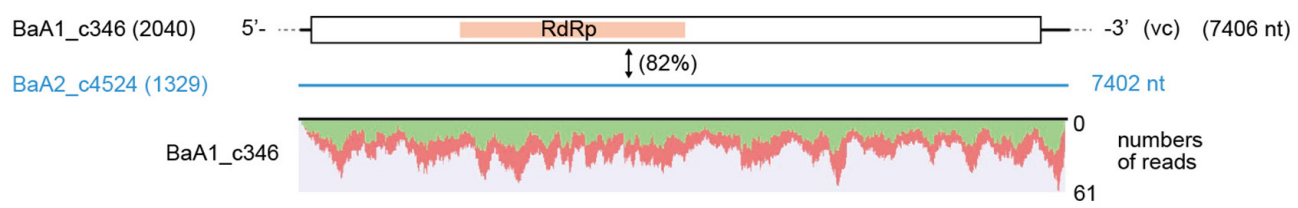

B

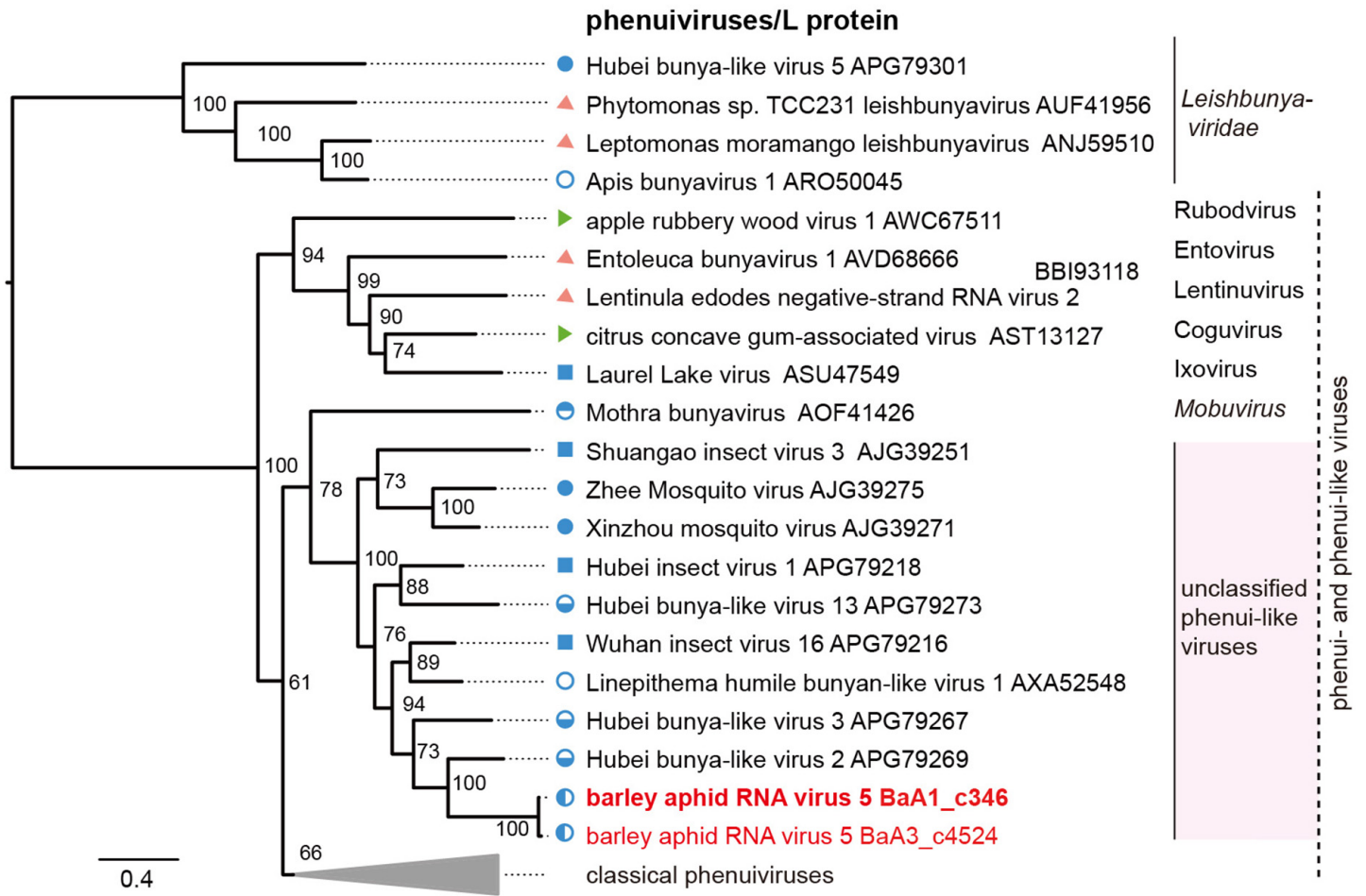

Host or potential host species

O Hymenoptera Diptera O Hemiptera O Odonata @Lepidoptera — other arthropods or arthropod/insect mix

(4) Insects mix 4 (including aphid samples) $>$ plants $\triangle$ fungi or unicellular eukaryotes

FIGURE 5 | The genome organization and phylogenetic relationships of phenui- and phenui-like viruses. (A) The genome structure of the putative $L$ segments of a phenui-like virus (named barley aphid RNA virus 5, BARV-5) identified from Rhopalosiphum padi, R. maidis, and Sitobion avenae or R. maidis transcriptomes. The conserved domain for viral $L$ proteins is shown as a red highlight within the ORF (RNA-dependent RNA polymerase, RdRp). Virus-like contigs in this study are shown as a black bar or a blue line, together with their read numbers in parentheses, and the nucleotide sequence identity between two virus-like contigs is shown. Read depth coverage throughout the assembled virus contig is shown below the schematic structure of the viral genome. (B) Phylogenetic relationships of BARV-5 and other selected phenuiviruses (family Phenuiviridae) and phenui-like viruses. The ML phylogenetic tree was constructed using a multiple amino acid sequence alignment of the $L$ proteins or its candidate sequences. The selected members of the genera within the family Phenuiviridae are displayed as a collapsed triangle (see Supplementary Table S3 for the virus names in the collapsed triangle). Some members of family Leishbuniyaviridae were used as the outgroups. The scale bar represents amino acid distances. The numbers at the nodes are bootstrap values of $>50 \%$.

that potentially encodes a reverse-ORF, as previous studies have proposed for some narna-like viruses, such as Hubei narna-like virus 21 and Zhejiang mosquito virus 3 (Cook et al., 2013; DeRisi et al., 2019; Dinan et al., 2020; Figure 6A). In the phylogenetic tree, BARV-6 and -7 grouped together with yeast narnaviruses (family Narnaviridae) and many invertebrate-associated narnalike viruses (Figure 6B).

Two dsRNA virus-like contigs (BaA2_c19028 and BaA2_c18060) were derived from an $R$. maidis colony from the 2016 sample (Table 2, Figure 6C, and Supplementary Figures S2B and data not shown). According to BlastP search results, both sequences were most closely related to the segments S1 and S4 of Shuangao chryso-like virus 1, with $37 \%$ and $24 \%$ amino acid sequence identities, respectively (Shi et al., 2016a) (Supplementary Table S4). However, we did not find the possible segments corresponding to S2 and S3. We tentatively named this chryso-like virus as barley aphid RNA virus 8 (BARV-8). Phylogenetically, chrysoviruses are grouped into two distinct 
A barley aphid RNA virus 6 BaR2_c1487 (4820)

$$
\text { RdRp }
$$

barley aphid RNA virus 7

BaR3_c16152 (239)

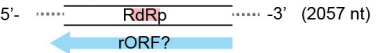

B narna- and narna-like viruses/RdRp

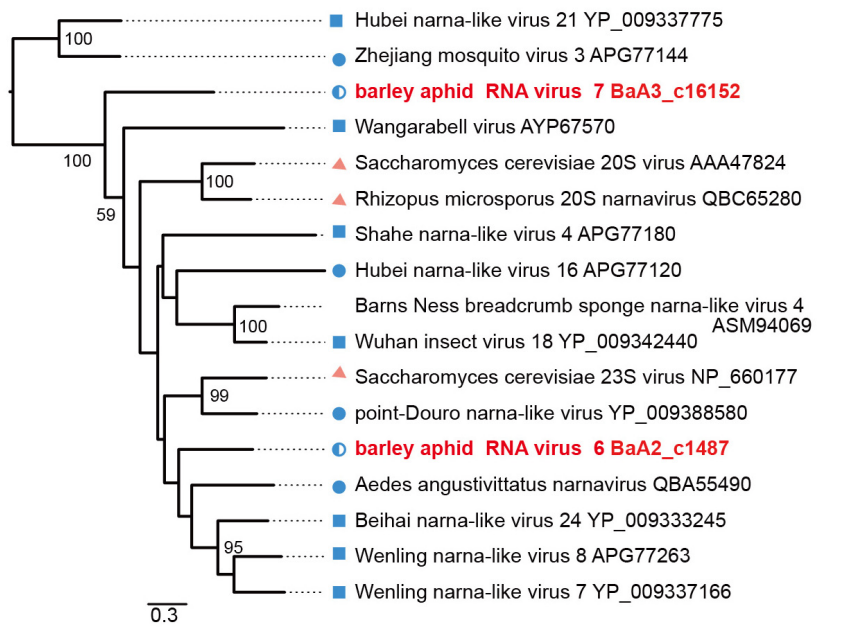

C

barley aphid RNA virus 8

BaR2_c19028 (660)

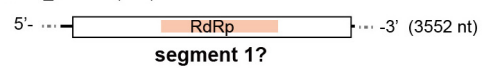

segment 1?
BaR2_c18060 (575)
5'-...

segment 4 ? ....... -3' (3220 nt)

D chryso- and chryso-like viruses/RdRp

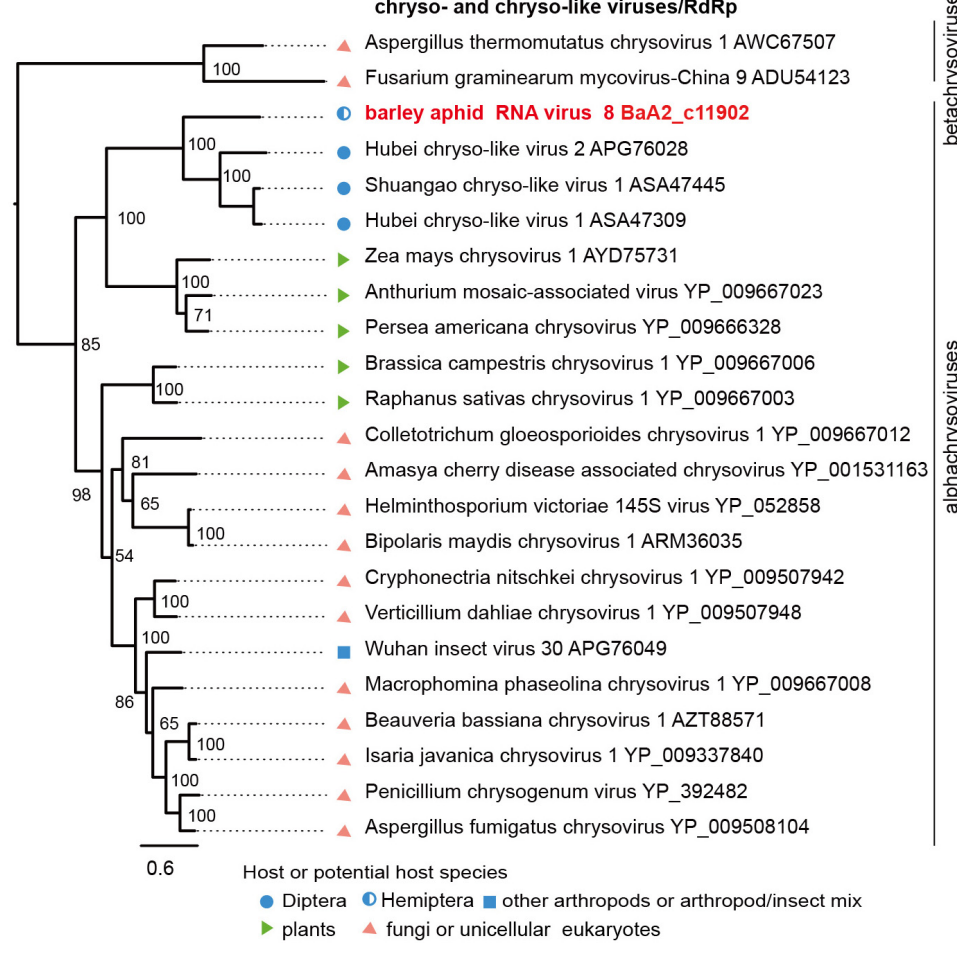

FIGURE 6 | Genome organizations and phylogenetic relationships of narna- and narna-like viruses (A,B) and chryso-and chryso-like viruses (C,D). (A,C) The genome structures of two novel narna-like viruses (named barley aphid RNA virus 6 and 7, BARV-6 and -7) in panel (A) and a chryso-like virus (named barley aphid RNA virus 8, BARV-8) in panel (C). rORF: reverse-frame ORF. (B,D) Phylogenetic relationships of two novel narna-like viruses BARV-6 and -7, yeast narnaviruses and invertebrate narna-like viruses (B), and BARV-8, chrysoviruses (the members of genus Alphachrysovirus) and chryso-like viruses (D). The ML trees were constructed using multiple amino acid sequence alignments of the RdRp sequences. Two narna-like viruses (Zhejiang mosquito virus 3 and Hubei narna-like virus 21) (B) or some members of genus Betachrysovirus (D) were used as the outgroups, respectively. The scale bar represents amino acid distances. The numbers at the nodes are bootstrap values of $>50 \%$. 
clusters that are currently classified into Alphachrysovirus and Betachrysovirus (Kotta-Loizou et al., 2020; Figure 6D). BARV-8 (S1 segment, RdRp) is placed within the clade of alphachrysoviruses and forms a subclade with chryso-like viruses derived from dipterans (Shi et al., 2016a). In addition, in two aphid colonies (R. maidis and probably R. padi) from the 2016 sample, we also identified another dsRNA virus-like sequence (BaA2_21290, a $1.3 \mathrm{~kb}$ fragment) (Table 2 and Supplementary Figure S2B) whose RdRp sequence was closely related to that of invertebrate alphapartiti-like viruses (Hubei partiti-like virus $25-28,55 \%-66 \%$ amino acid identities) from spiders or dragonflies (Shi et al., 2016a) and alphapartitiviruses that infect plant and filamentous fungi (Supplementary Table S4 and data not shown).

\section{CONCLUSION}

In the current study, we discovered at least 60 virus-like sequences related to nege/kita-, flavi/ jingmen-, tombus-, phenui-, mononega-, narna-, chryso-, partiti-, and luteoviruses from 15 aphid population samples ( $R$. padi, R. maidis, and $S$. avenae) that were collected from a barley field in the spring of 2016, 2017, and 2018. From these sequences we identified eight potentially novel RNA viruses belonging to nege/kita-, flavi-, phenui-, mononega-, narna- and chrysovirus lineages, as well as some previously described RNA viruses. Moreover, based on the phylogenetic analyses, we proposed novel genera, Centivirus and Aphiglyvirus, for aphid associated nege/kita-like viruses and their relatives. Our data provide novel information on the diversity of aphid-associated viruses in aphid populations infesting the barley field. Our study, along with others, has discovered that some aphid-associated viruses are present in different aphid species and in plant-derived samples. This raises the speculation that aphid-associated viruses may be distributed across varieties of aphid species, with plants being the reservoirs. Since aphid viruslike sequences are also present in the hyperparasitoid wasp, it would also be interesting to explore the possible horizontal transmission of viruses between aphids and primary parasitoids and/or hyperparasitoids. To deepen our understanding on the population dynamics and spread of aphid viruses in the field, investigation of horizontal virus transmissions between insects and plants as well as between insects and their parasitoids is an important topic for future research. Some aphid viruses cause diseases in their hosts, for example, rapid population decline and phenotype alternations of insect performances (Williamson et al., 1988; vandenHeuvel et al., 1997; Moon et al., 1998; van Munster et al., 2002), implying their potentiality to be used as biological control agents against aphid pests (van Munster et al., 2005; Feng et al., 2017). On the other hand, a densovirus (DplDNV) that induces the production of winged morphs in the rosy apple aphids (Ryabov et al., 2009) is regarded as a conditionally mutualistic symbiont because this relationship facilitates the movement of aphids between the host plants (Roossinck, 2011, 2015). Moreover, a recent study reported that an insect virus (APV) facilitates host aphid adaptation to the host plant by suppressing the plant's defense response, demonstrating the unique interactions among virus, aphid and plant ( $\mathrm{Lu}$ et al., 2020). Our data lay the foundation for further exploration of the ecological roles of aphid-associated viruses in barley ecosystem, either in a beneficial or harmful way as mentioned above. The physiological and ecological roles of aphid-specific viruses in aphid populations in the field warrant further investigation.

\section{DATA AVAILABILITY STATEMENT}

The virus and virus-like sequences derived from this study can be found in GenBank under the accession numbers LC516834 LC516856.

\section{AUTHOR CONTRIBUTIONS}

HK designed the experiments and analyzed the data and wrote the manuscript. $\mathrm{HH}$ and $\mathrm{HK}$ collected the samples. $\mathrm{HK}, \mathrm{MF}, \mathrm{HH}$, $\mathrm{KH}$, IA, and NS performed the experimental work. IA and NS were involved in discussion and manuscript revision. All authors have given approval to the final version of the manuscript.

\section{FUNDING}

This study was supported by the Grants-in-Aids for Scientific Research (C) (KAKENHI 15K07312) to HK and NS; and Scientific Research on Innovative Areas (16H06436, 16H06429, and $16 \mathrm{H} 21723$ ) to NS and HK from the Ministry of Education, Culture, Sports, Science and Technology (MEXT) of Japan; and a Joint Research Grant to $\mathrm{HH}$ and HK by the Ohara Foundation for Agriculture Research, Kurashiki, Japan.

\section{ACKNOWLEDGMENTS}

We would like to thank Sakae Hisano, Kazuyuki Maruyama, Hideki Nishimura, Takakazu Matsuura, and Makoto Ishii for their helpful technical assistance. We also thank the handling editor and two reviewers for their assistances and valuable suggestions. Rhopalosiphum padi DNA sequencing data were obtained from AphidBase, which acknowledges funding from the European Research Council (Grant No. APHIDHOST-310190 to Dr. Jorunn Bos at the James Hutton Institute). The barley samples were provided by the National BioResource Project for barley (Principal Investigator Prof. Kazuhiro Sato), run by the Ministry of Education, Culture, Sports, Science and Technology (MEXT), Japan. We are also grateful to all researchers who have shared their sequence data deposited in publicly available databases before publication.

\section{SUPPLEMENTARY MATERIAL}

The Supplementary Material for this article can be found online at: https://www.frontiersin.org/articles/10.3389/fmicb.2020. 00509/full\#supplementary-material 


\section{REFERENCES}

Ban, L., Didon, A., Jonsson, L. M. V., Glinwood, R., and Delp, G. (2007). An improved detection method for the Rhopalosiphum padi virus (RhPV) allows monitoring of its presence in aphids and movement within plants. J. Virol. Methods 142, 136-142. doi: 10.1016/j.jviromet.2007.01.014

Bekal, S., Domier, L. L., Gonfa, B., McCoppin, N. K., Lambert, K. N., and Bhalerao, K. (2014). A novel flavivirus in the soybean cyst nematode. J. Gen. Virol. 95, 1272-1280. doi: 10.1099/vir.0.060889-0

Bigot, D., Dalmon, A., Roy, B., Hou, C. S., Germain, M., Romary, M., et al. (2017) The discovery of Halictivirus resolves the Sinaivirus phylogeny. J. Gen. Virol. 98, 2864-2875. doi: 10.1099/jgv.0.000957

Bolling, B. G., Weaver, S. C., Tesh, R. B., and Vasilakis, N. (2015). Insect-specific virus discovery: significance for the arbovirus community. Viruses 7, 49114928. doi: 10.3390/v7092851

Brault, V., Uzest, M., Monsion, B., Jacquot, E., and Blanc, S. (2010). Aphids as transport devices for plant viruses. C. R. Biol. 333, 524-538. doi: 10.1016/j.crvi. 2010.04.001

Chen, Y., Pike, K. S., Greenstone, M. H., and Shufran, K. A. (2006). Molecular markers for identification of the hyperparasitoids Dendrocerus carpenteri and Alloxysta xanthopsis in Lysiphlebus testaceipes parasitizing cereal aphids. Biocontrol 51, 183-194. doi: 10.1007/s10526-005-1518-0

Colmant, A. M., O'Brien, C. A., Newton, N. D., Watterson, D., Hardy, J., Coulibaly, F., et al. (2020). Novel monoclonal antibodies against Australian strains of negeviruses and insights into virus structure, replication and host-restriction. J. Gen. Virol. doi: 10.1099/jgv.0.001388 [Epub ahead of print],

Cook, S., Chung, B. Y. W., Bass, D., Moureau, G., Tang, S. Y., McAlister, E., et al. (2013). Novel virus discovery and genome reconstruction from field RNA samples reveals highly divergent viruses in dipteran hosts. PloS One 8:e80720. doi: 10.1371/journal.pone. 0080720

Dader, B., Then, C., Berthelot, E., Ducousso, M., Ng, J. C. K., and Drucker, M. (2017). Insect transmission of plant viruses: multilayered interactions optimize viral propagation. Insect Sci. 24, 929-946. doi: 10.1111/1744-7917.12470

Debat, H. J. (2017). An RNA virome associated to the golden orb-weaver spider Nephila clavipes. Front. Microbiol. 8:2097. doi: 10.3389/fmicb.2017.02097

DeRisi, J. L., Huber, G., Kistler, A., Retallack, H., Wilkinson, M., and Yllanes, D. (2019). An exploration of ambigrammatic sequences in narnaviruses. Sci. Rep. 9:17982. doi: 10.1038/s41598-019-54181-3

Dinan, A. M., Lukhovitskaya, N. I., Olendraite, I., and Firth, A. E. (2020). A case for a negative-strand coding sequence in a group of positive-sense RNA viruses. Virus Evol. 6:veaa007. doi: 10.1093/ve/veaa007

Fan, G., Wang, L., Deng, M., Zhao, Z., Dong, Y., Zhang, X., et al. (2016). Changes in transcript related to osmosis and intracellular ion homeostasis in Paulownia tomentosa under salt stress. Front. Plant Sci. 7:384. doi: 10.3389/fpls.2016.00384

Fauver, J. R., Akter, S., Morales, A. I. O., Black, W. C., Rodriguez, A. D., Stenglein, M. D., et al. (2019). A reverse-transcription/RNase H based protocol for depletion of mosquito ribosomal RNA facilitates viral intrahost evolution analysis, transcriptomics and pathogen discovery. Virology 528, 181-197. doi: 10.1016/j.virol.2018.12.020

Feng, Y., Krueger, E. N., Liu, S., Dorman, K., Bonning, B. C., and Miller, W. A. (2017). Discovery of known and novel viral genomes in soybean aphid by deep sequencing. Phytobiomes 1, 36-45. doi: 10.1094/PBIOMES-11-16-0013-R

Foottit, R. G., Maw, H. E. L., Von Dohlen, C. D., and Hebert, P. D. N. (2008). Species identification of aphids (Insecta: Hemiptera: Aphididae) through DNA barcodes. Mol. Ecol. Resour. 8, 1189-1201. doi: 10.1111/j.1755-0998.2008. 02297.x

François, S., Bernardo, P., Filloux, D., Roumagnac, P., Yaverkovski, N., Froissart, R., et al. (2014). A novel itera-like densovirus isolated by viral metagenomics from the sea barley Hordeum marinum. Genome Announc. 2, e01196-14. doi: 10.1128/genomeA.01196-14

Freitas-Astua, J., Ramos-Gonzalez, P. L., Arena, G. D., Tassi, A. D., and Kitajima, E. W. (2018). Brevipalpus-transmitted viruses: parallelism beyond a common vector or convergent evolution of distantly related pathogens? Curr. Opin. Virol. 33, 66-73. doi: 10.1016/j.coviro.2018.07.010

Fujita, R., Kuwata, R., Kobayashi, D., Bertuso, A. G., Isawa, H., and Sawabe, K. (2017). Bustos virus, a new member of the negevirus group isolated from a Mansonia mosquito in the Philippines. Arch. Virol. 162, 79-88. doi: 10.1007/ s00705-016-3068-4
Gildow, F. E., and Darcy, C. J. (1988). Barley and oats as reservoirs for an aphid virus and the influence on barley yellow dwarf virus transmission. Phytopathology $78,811-816$.

Granberg, F., Vicente-Rubiano, M., Rubio-Guerri, C., Karlsson, O. E., Kukielka, D., Belak, S., et al. (2013). Metagenomic detection of viral pathogens in Spanish honeybees: co-infection by aphid lethal paralysis, Israel acute paralysis and Lake Sinai viruses. PloS One 8:e57459. doi: 10.1371/journal.pone.0057459

Guindon, S., Dufayard, J. F., Lefort, V., Anisimova, M., Hordijk, W., and Gascuel, O. (2010). New algorithms and methods to estimate maximum-likelihood phylogenies: assessing the performance of PhyML 3.0. Sys. Biol. 59, 307-321. doi: 10.1093/sysbio/syq010

Hao, X. Y., Zhang, W. F., Zhao, F. M., Liu, Y., Qian, W. J., Wang, Y. C., et al. (2018). Discovery of plant viruses from tea plant (Camellia sinensis (L.) O. Kuntze) by metagenomic sequencing. Front. Microbiol. 9:2175. doi: 10.3389/fmicb.2018. 02175

Holler, C., Borgemeister, C., Haardt, H., and Powell, W. (1993). The relationship between primary parasitoids and hyperparasitoids of cereal aphids - an analysis of field data. J. Anim. Ecol. 62, 12-21. doi: 10.2307/5478

Jarosova, J., Chrpova, J., Sip, V., and Kundu, J. K. (2013). A comparative study of the barley yellow dwarf virus species PAV and PAS: distribution, accumulation and host resistance. Plant Pathol. 62, 436-443. doi: 10.1111/j.1365-3059.2012. 02644.x

Jia, N., Liu, H. B., Ni, X. B., Bell-Sakyi, L., Zheng, Y. C., Song, J. L., et al. (2019). Emergence of human infection with Jingmen tick virus in China: a retrospective study. EBioMedicine 43, 317-324. doi: 10.1016/j.ebiom.2019.04.004

Kallies, R., Kopp, A., Zirkel, F., Estrada, A., Gillespie, T. R., Drosten, C., et al. (2014). Genetic characterization of goutanap virus, a novel virus related to negeviruses, cileviruses and higreviruses. Viruses 6, 4346-4357. doi: 10.3390/v6114346

Katoh, K., and Standley, D. M. (2013). MAFFT multiple sequence alignment software version 7: improvements in performance and usability. Mol. Biol. Evol. 30, 772-780. doi: 10.1093/molbev/mst010

Kawakami, K., Kurnia, Y. W., Fujita, R., Ito, T., Isawa, H., Asano, S., et al. (2016). Characterization of a novel negevirus isolated from Aedes larvae collected in a subarctic region of Japan. Arch. Virol. 161, 801-809. doi: 10.1007/s00705-0152711-9

King, A. M. Q., Adams, M. J., Carstens, E. B., and Lefkowitz, E. J. (2011). Virus Taxonomy: Ninth Report of the International Committee on Taxonomy of Viruses. San Diego: Elsevier Academic Press.

Kobayashi, K., Atsumi, G., Iwadate, Y., Tomita, R., Chiba, K., Akasaka, S., et al. (2013). Gentian Kobu-sho-associated virus: a tentative, novel double-stranded RNA virus that is relevant to gentian Kobu-sho syndrome. J. Gen. Plant Pathol. 79, 56-63. doi: 10.1007/s10327-012-0423-5

Kondo, H., Chiba, S., Maruyama, K., Andika, I. B., and Suzuki, N. (2019). A novel insect-infecting virga/nege-like virus group and its pervasive endogenization into insect genomes. Virus Res. 262, 37-47. doi: 10.1016/j.virusres.2017. 11.020

Kondo, H., Chiba, S., and Suzuki, N. (2015). "Detection and analysis of nonretroviral RNA virus-like elements in plant, fungal, and insect genomes," in Plant Virology Protocols -New Approaches to Detect Viruses and Host Responses, eds I. Uyeda and C. Masuta (New York, NY: Springer), 73-88. doi: 10.1007/9781-4939-1743-3_7

Kondo, H., Hirota, K., Maruyama, K., Andika, I. B., and Suzuki, N. (2017). A possible occurrence of genome reassortment among bipartite rhabdoviruses. Virology 508, 18-25. doi: 10.1016/j.virol.2017.04.027

Kondo, H., Hisano, S., Chiba, S., Maruyama, K., Andika, I. B., Toyoda, K., et al. (2016). Sequence and phylogenetic analyses of novel totivirus-like doublestranded RNAs from field-collected powdery mildew fungi. Virus Res. 213 353-364. doi: 10.1016/j.virusres.2015.11.015

Koramutla, M. K., Aminedi, R., and Bhattacharya, R. (2016). Comprehensive evaluation of candidate reference genes for qRT-PCR studies of gene expression in mustard aphid, Lipaphis erysimi (Kalt). Sci. Rep. 6:25883. doi: 10.1038/ srep25883

Kotta-Loizou, I., Castón, J. R., Coutts, R. H. A., Hillman, B. I., Jiang, D., Kim, D. H., et al. (2020). ICTV virus taxonomy profile: Chrysoviridae. J. Gen. Virol. 101, 143-144. doi: 10.1099/jgv.0.001383

Krogh, A., Larsson, B., von Heijne, G., and Sonnhammer, E. L. L. (2001). Predicting transmembrane protein topology with a hidden Markov model: application to complete genomes. J. Mol. Biol. 305, 567-580. doi: 10.1006/jmbi.2000.4315 
Krueger, E. N., Beckett, R. J., Gray, S. M., and Miller, W. A. (2013). The complete nucleotide sequence of the genome of barley yellow dwarf virus-RMV reveals it to be a new Polerovirus distantly related to other yellow dwarf viruses. Front. Microbiol. 4:205. doi: 10.3389/fmicb.2013.00205

Kuchibhatla, D. B., Sherman, W. A., Chung, B. Y. W., Cook, S., Schneider, G., Eisenhaber, B., et al. (2014). Powerful sequence similarity search methods and in-depth manual analyses can identify remote homologs in many apparently “orphan” viral proteins. J. Virol. 88, 10-20. doi: 10.1128/JVI.02595-13

Lefort, V., Longueville, J. E., and Gascuel, O. (2017). SMS: smart model selection in PhyML. Mol. Biol. Evol. 34, 2422-2424. doi: 10.1093/molbev/msx149

Lin, Y. H., Fujita, M., Chiba, S., Hyodo, K., Andika, I. B., Suzuki, N., et al. (2019). Two novel fungal negative-strand RNA viruses related to mymonaviruses and phenuiviruses in the shiitake mushroom (Lentinula edodes). Virology 533, 125-136. doi: 10.1016/j.virol.2019.05.008

Locali-Fabris, E. C., Freitas-Astua, J., Souza, A. A., Takita, M. A., Astua-Monge, G., Antonioli-Luizon, R., et al. (2006). Complete nucleotide sequence, genomic organization and phylogenetic analysis of Citrus leprosis virus cytoplasmic type. J. Gen. Virol. 87, 2721-2729. doi: 10.1099/vir.0.82038-0

Lu, H., Zhu, J., Yu, J., Chen, X., Kang, L., and Cui, F. (2020). A symbiotic virus facilitates aphid adaptation to host plants by suppressing jasmonic acid responses. Mol. Plant Microbe Interact. 31, 55-65. doi: 10.1094/MPMI-01-190016- R

Lüthi, M. N., Vorburger, C., and Dennis, A. B. (2019). A novel RNA virus in the parasitoid wasp Lysiphlebus fabarum: genomic structure, prevalence, and transmission. Viruses 12:59. doi: 10.3390/v12010059

Maina, S., Edwards, O. R., de Almeida, L., Ximenes, A., and Jones, R. A. C. (2017). Metagenomic analysis of cucumber RNA from east timor reveals an Aphid lethal paralysis virus genome. Genome Announc. 5:e01445-16. doi: 10.1128/ genomeA.01445-16

Medd, N. C., Fellous, S., Waldron, F. M., Xuereb, A., Nakai, M., Cross, J. V., et al. (2018). The virome of Drosophila suzukii, an invasive pest of soft fruit. Virus Evol. 4:vey009. doi: 10.1093/ve/vey009

Melzer, M. J., Simbajon, N., Carillo, J., Borth, W. B., Freitas-Astua, J., Kitajima, E. W., et al. (2013). A cilevirus infects ornamental hibiscus in Hawaii. Arch. Virol. 158, 2421-2424. doi: 10.1007/s00705-013-1745-0

Miller, W. A., Liu, S. J., and Beckett, R. (2002). Barley yellow dwarf virus: Luteoviridae or Tombusviridae? Mol. Plant Pathol. 3, 177-183. doi: 10.1046/j. 1364-3703.2002.00112.x

Moon, J. S., Domier, L. L., McCoppin, N. K., D’Arcy, C. J., and Jin, H. (1998). Nucleotide sequence analysis shows that Rhopalosiphum padi virus is a member of a novel group of insect-infecting RNA viruses. Virology 243, 54-65. doi: 10.1006/viro.1998.9043

Muhire, B. M., Varsani, A., and Martin, D. P. (2014). SDT: a virus classification tool based on pairwise sequence alignment and identity calculation. PloS One 9:e108277. doi: 10.1371/journal.pone.0108277

Nabeshima, T., Inoue, S., Okamoto, K., Posadas-Herrera, G., Yu, F. X., Uchida, L., et al. (2014). Tanay virus, a new species of virus isolated from mosquitoes in the Philippines. J. Gen. Virol. 95, 1390-1395. doi: 10.1099/vir.0.061887-0

Navarro, B., Minutolo, M., De Stradis, A., Palmisano, F., Alioto, D., and Di Serio, F. (2018). The first phlebo-like virus infecting plants: a case study on the adaptation of negative-stranded RNA viruses to new hosts. Mol. Plant Pathol. 19, 1075-1089. doi: 10.1111/mpp.12587

Ng, J. C. K., and Perry, K. L. (2004). Transmission of plant viruses by aphid vectors. Mol. Plant Pathol. 5, 505-511. doi: 10.1111/j.1364-3703.2004.00240.x

Nunes, M. R. T., Contreras-Gutierrez, M. A., Guzman, H., Martins, L. C., Barbirato, M. F., Savit, C., et al. (2017). Genetic characterization, molecular epidemiology, and phylogenetic relationships of insect-specific viruses in the taxon Negevirus. Virology 504, 152-167. doi: 10.1016/j.virol.2017.01.022

O’Brien, C. A., McLean, B. J., Colmant, A. M. G., Harrison, J. J., Hall-Mendelin, S., van den Hurk, A. F., et al. (2017). Discovery and characterisation of Castlerea virus, a new species of Negevirus isolated in Australia. Evol. Bioinform. 13:1176934317691269. doi: 10.1177/1176934317691269

Parry, H. R., Macfadyen, S., and Kriticos, D. J. (2012). The geographical distribution of yellow dwarf viruses and their aphid vectors in Australian grasslands and wheat. Australas. Plant Pathol. 41, 375-387. doi: 10.1007/s13313-012-0133-7

Pettersson, J. H. O., Shi, M., Eden, J. S., Holmes, E. C., and Hesson, J. C. (2019). Meta-transcriptomic comparison of the RNA viromes of the mosquito vectors
Culex pipiens and Culex torrentium in Northern Europe. Viruses 11:E1033. doi: $10.3390 / \mathrm{v} 11111033$

Powell, G., Tosh, C. R., and Hardie, J. (2006). Host plant selection byaphids: behavioral, evolutionary, and applied perspectives. Ann. Rev. Entomol. 51, 309-330. doi: 10.1146/annurev.ento.51.110104.151107

Ramos-González, P. L., Santos, G. F. D., Chabi-Jesus, C., Harakava, R., Kitajima, E. W., and Freitas-Astúa, J. (2020). Passion fruit green spot virus genome harbors a new orphan ORF and highlights the flexibility of the 5'-end of the RNA2 segment across cileviruses. Front. Microbiol. 11:206. doi: 10.3389/fmicb. 2020.00206

Reineke, A., and Asgari, S. (2005). Presence of a novel small RNA-containing virus in a laboratory culture of the endoparasitic wasp Venturia canescens (Hymenoptera : Ichneumonidae). J. Insect Physiol. 51, 127-135. doi: 10.1016/ j.jinsphys.2004.05.005

Remnant, E. J., Shi, M., Buchmann, G., Blacquiere, T., Holmes, E. C., Beekman, M., et al. (2017). A diverse range of novel RNA viruses in geographically distinct honey bee populations. J. Virol. 91:e00158-17. doi: 10.1128/JVI.00158-17

Roossinck, M. J. (2011). The good viruses: viral mutualistic symbioses. Nat. Rev. Microbiol. 9, 99-108. doi: 10.1038/nrmicro2491

Roossinck, M. J. (2015). Plants, viruses and the environment: ecology and mutualism. Virology 479, 271-277. doi: 10.1016/j.virol.2015.03.041

Roumi, V., Caglayan, K., Gazel, M., and Li, S. (2020). Complete genome sequence of Aphid lethal paralysis virus from metagenomic analysis of Cestrum elegans small RNAs. Gene Rep. 18:100566. doi: 10.1016/j.genrep.2019.100566

Ryabov, E. V. (2007). A novel virus isolated from the aphid Brevicoryne brassicae with similarity to Hymenoptera picorna-like viruses. J. Gen. Virol. 88, 2590 2595. doi: 10.1099/vir.0.83050-0

Ryabov, E. V., Keane, G., Naish, N., Evered, C., and Winstanley, D. (2009). Densovirus induces winged morphs in asexual clones of the rosy apple aphid, Dysaphis plantaginea. Proc. Natl. Acad. Sci. U.S.A. 106, 8465-8470. doi: 10.1073/ pnas.0901389106

Sadeghi, M., Altan, E., Deng, X. T., Barker, C. M., Fang, Y., Coffey, L. L., et al. (2018). Virome of $>12$ thousand Culex mosquitoes from throughout California. Virology 523, 74-88. doi: 10.1016/j.virol.2018.07.029

Saitou, N., and Nei, M. (1987). The neighbor-joining method - a new method for reconstructing phylogenetic trees. Mol. Biol. Evol. 4, 406-425. doi: 10.1093/ oxfordjournals.molbev.a040454

Schoonvaere, K., Smagghe, G., Francis, F., and de Graaf, D. C. (2018). Study of the metatranscriptome of eight social and solitary wild bee species reveals novel viruses and bee parasites. Front. Microbiol. 9:177. doi: 10.3389/fmicb. 2018.00177

Shi, M., Lin, X. D., Tian, J. H., Chen, L. J., Chen, X., Li, C. X., et al. (2016a). Redefining the invertebrate RNA virosphere. Nature 7634, 539-543. doi: 10. 1038/nature20167

Shi, M., Lin, X. D., Vasilakis, N., Tian, J. H., Li, C. X., Chen, L. J., et al. (2016b). Divergent viruses discovered in arthropods and vertebrates revise the evolutionary history of the Flaviviridae and related viruses. J. Virol. 90, 659-669. doi: 10.1128/JVI.02036-15

Shi, M., Neville, P., Nicholson, J., Eden, J. S., Imrie, A., and Holmes, E. C. (2017). High-resolution metatranscriptomics reveals the ecological dynamics of mosquito-associated RNA viruses in Western Australia. J. Virol. 91:e00680-17. doi: 10.1128/JVI.00680-17

Solovyev, A. G., and Morozov, S. Y. (2017). Non-replicative integral membrane proteins encoded by plant alpha-like viruses: emergence of diverse orphan ORFs and movement protein genes. Front. Plant Sci. 8:1820. doi: 10.3389/fpls. 2017.01820

Talavera, G., and Castresana, J. (2007). Improvement of phylogenies after removing divergent and ambiguously aligned blocks from protein sequence alignments. Syst. Biol. 56, 564-577. doi: 10.1080/10635150701472164

Tassi, A. D., Garita-Salazar, L. C., Amorim, L., Novelli, V. M., Freitas-Astua, J., Childers, C. C., et al. (2017). Virus-vector relationship in the Citrus leprosis pathosystem. Exp. Appl. Acarol. 71, 227-241. doi: 10.1007/s10493-017-0123-0

Teixeira, M., Sela, N., Ng, J., Casteel, C. L., Peng, H. C., Bekal, S., et al. (2016). A novel virus from Macrosiphum euphorbiae with similarities to members of the family Flaviviridae. J. Gen. Virol. 97, 1261-1271. doi: 10.1099/jgv.0.000414

Teixeira, M. A., Sela, N., Atamian, H. S., Bao, E., Chaudhary, R., MacWilliams, J., et al. (2018). Sequence analysis of the potato aphid Macrosiphum euphorbiae 
transcriptome identified two new viruses. PloS One 13:e0193239. doi: 10.1371/ journal.pone.0193239

Temmam, S., Bigot, T., Chrétien, D., Gondard, M., Pérot, P., Pommelet, V., et al. (2019). Insights into the host range, genetic diversity, and geographical distribution of jingmenviruses. mSphere 4:e00645-19. doi: 10.1128/mSphere. 00645-19

Tokarz, R., Sameroff, S., Tagliafierro, T., Jain, K., Williams, S. H., Cucura, D. M., et al. (2018). Identification of novel viruses in Amblyomma americanum, Dermacentor variabilis, and Ixodes scapularis ticks. mSphere 3:e0614-17. doi: 10.1128/mSphere.00614-17

van Munster, M., Dullemans, A. M., Verbeek, M., van den Heuvel, J., Clerivet, A., and van der Wilk, F. (2002). Sequence analysis and genomic organization of Aphid lethal paralysis virus: a new member of the family Dicistroviridae. J. Gen. Virol. 83, 3131-3138. doi: 10.1099/0022-1317-83-12-3131

van Munster, M., Dullemans, A. M., Verbeek, M., van den Heuvel, J., Reinbold, C., Brault, V., et al. (2003). A new virus infecting Myzus persicae has a genome organization similar to the species of the genus Densovirus. J. Gen. Virol. 84, 165-172. doi: 10.1099/vir.0.18650-0

van Munster, M., Janssen, A., Clérivet, A., and Van den Heuvel, J. (2005). Can plants use an entomopathogenic virus as a defense against herbivores? Oecologia 143, 396-401. doi: 10.1007/s00442-004-1818-6

vandenHeuvel, J., Hummelen, H., Verbeek, M., Dullemans, A. M., and vanderWilk, F. (1997). Characteristics of Acyrthosiphon pisum virus, a newly identified virus infecting the pea aphid. J. Invertebr. Pathol. 70, 169-176. doi: 10.1006/jipa.1997. 4691

Vasilakis, N., Forrester, N. L., Palacios, G., Nasar, F., Savji, N., Rossi, S. L., et al. (2013). Negevirus: a proposed new taxon of insect-specific viruses with wide geographic distribution. J. Virol. 87, 2475-2488. doi: 10.1128/JVI.00776- 12

Vasilakis, N., and Tesh, R. B. (2015). Insect-specific viruses and their potential impact on arbovirus transmission. Curr. Opin. Virol. 15, 69-74. doi: 10.1016/ j.coviro.2015.08.007

Viljakainen, L., Holmberg, I., Abril, S., and Jurvansuu, J. (2018). Viruses of invasive Argentine ants from the European main supercolony: characterization, interactions and evolution. J. Gen. Virol. 99, 1129-1140. doi: 10.1099/jgv.0. 001104

Walker, P. J., Siddell, S. G., Lefkowitz, E. J., Mushegian, A. R., Dempsey, D. M., Dutilh, B. E., et al. (2019). Changes to virus taxonomy and the International Code of Virus Classification and Nomenclature ratified by the International Committee on Taxonomy of Viruses (2019). Arch. Virol. 164, 2417-2429. doi: 10.1007/s00705-019-04306-w

Wamonje, F. O., Michuki, G. N., Braidwood, L. A., Njuguna, J. N., Mutuku, J. M., Djikeng, A., et al. (2017). Viral metagenomics of aphids present in bean and maize plots on mixed-use farms in Kenya reveals the presence of three dicistroviruses including a novel big Sioux River virus-like dicistrovirus. Virol. J. 14, 188. doi: 10.1186/s12985-017-0854-x

Webster, C. L., Longdon, B., Lewis, S. H., and Obbard, D. J. (2016). Twenty-five new viruses associated with the Drosophilidae (Diptera). Evol. Bioinform. 12, 13-25. doi: 10.4137/EBO.S39454

Webster, C. L., Waldron, F. M., Robertson, S., Crowson, D., Ferrari, G., Quintana, J. F., et al. (2015). The discovery, distribution, and evolution of viruses associated with Drosophila melanogaster. PloS Biol. 13:e1002210. doi: 10.1371/ journal.pbio. 1002210

Whitfield, A. E., Falk, B. W., and Rotenberg, D. (2015). Insect vector-mediated transmission of plant viruses. Virology 479, 278-289. doi: 10.1016/j.virol.2015. 03.026

Whitfield, A. E., Huot, O. B., Martin, K. M., Kondo, H., and Dietzgen, R. G. (2018). Plant rhabdoviruses-their origins and vector interactions. Curr. Opin. Virol. 33, 198-207. doi: 10.1016/j.coviro.2018.11.002

Williamson, C., Rybicki, E. P., Kasdorf, G. G. F., and Vonwechmar, M. B. (1988). Characterization of a new picorna-like virus isolated from aphids. J. Gen. Virol. 69, 787-795. doi: 10.1099/0022-1317-69-4-787

Yang, D. H., Zhao, H. X., Shi, J. M., Xu, X., Wu, Y. Y., Guo, R., et al. (2019). Discovery of aphid lethal paralysis virus in Vespa velutina and Apis cerana in China. Insects 10, 157. doi: 10.3390/insects 10060157

Zhang, W., Wu, T. F., Guo, M. M., Chang, T. Y., Yang, L., Tan, Y., et al. (2019). Characterization of a new bunyavirus and its derived small RNAs in the brown citrus aphid, Aphis citricidus. Virus Genes 55, 557-561. doi: 10.1007/s11262019-01667-x

Zhao, L., Mwaliko, C., Atoni, E., Wang, Y. J., Zhang, Y. Z., Zhan, J. B., et al. (2019). Characterization of a novel Tanay virus isolated from Anopheles sinensis mosquitoes in Yunnan, China. Front. Microbiol. 10:1963. doi: 10.3389/fmicb. 2019.01963

Conflict of Interest: The authors declare that the research was conducted in the absence of any commercial or financial relationships that could be construed as a potential conflict of interest.

Copyright (c) 2020 Kondo, Fujita, Hisano, Hyodo, Andika and Suzuki. This is an open-access article distributed under the terms of the Creative Commons Attribution License (CC BY). The use, distribution or reproduction in other forums is permitted, provided the original author(s) and the copyright owner(s) are credited and that the original publication in this journal is cited, in accordance with accepted academic practice. No use, distribution or reproduction is permitted which does not comply with these terms. 